\title{
Gestión de la diversidad. El reto millennial en un grupo de organizaciones: ¿quiénes son, qué los motiva y cómo retenerlos?
}

\section{Diversity management The millennial challenge in a group of organizations: who are they, what motivates them and how to retain them?}

Daniel Eduardo Mitta Flores

Pontificia Universidad Católica del Perú

daniel.mitta@pucp.pe 
Este artículo tiene como objetivo analizar las estrategias y políticas aplicables a un grupo de millennials profesionales y cómo estas representan un desafío para las organizaciones. La Generación Millennial tiene requerimientos y expectativas de sus centros laborales que pueden diferir de lo que estos ofrecen actualmente. Por esta razón, las áreas de recursos humanos deben conocer estas expectativas para lograr una eficiente retención del talento. Los retos y cambios que demandarán los integrantes de cada de generación en el futuro nos obligan a replantearnos estas cuestiones, siendo necesario promover estrategias y políticas que permitan que el colaborar se sienta identificado y fidelizado con la organización. En este contexto, el conocimiento de las características del personal es esencial, por lo que la identificación de los grupos generacionales que lo componen es clave para poder formular un plan de retención adecuado a cada organización debido a que, según la teoría generacional, cada grupo generacional cuenta con expectativas y características diferenciales.

Palabras clave: gestión de la diversidad, millennials, rango generacional, satisfacción laboral, retención de talento

This article aims to analyze the strategies and policies applicable to a group of professional millennials and how they represent a challenge for organizations. The Millennial Generation has requirements and expectations of their work centers that may be different from those currently offered. It is for this reason that the human resources areas must know about these expectations in order to achieve efficient retention of talent. The challenges and changes that will be demanded by the members of each generation in the future oblige us to rethink these issues, making necessary to promote strategies and policies that make the collaborators feel identified and loyal to the organization. In this context, the knowledge of the characteristics of the personnel is essential, so the identification of the generational groups that compose them is key to be able to formulate an adequate retention plan for each organization because, according to the generational theory, each generational group has different expectations and characteristics.

Keywords: diversity management, millennials, generational rank, job satisfaction, talent retention 


\section{Introducción}

Los millennials son una generación con atributos, necesidades y características diferentes a otras generaciones, lo cual significa que las estrategias e incentivos que las áreas de recursos humanos venían implementando no se aplican necesariamente a ellos. Es por esta razón que es necesario que las áreas de recursos humanos estén preparadas para afrontar estos nuevos desafíos en la retención del talento humano. Desde el punto de vista demográfico, podemos afirmar que existen millennials peruanos, pero, desde el punto de vista conductual, aún no se puede asegurar esto debido a que no se sabe si las características del comportamiento o sus expectativas laborales son similares o diferentes a las de los millennials norteamericanos.

Algunas de las quejas o problemas más frecuentes que presentan las organizaciones que cuentan con personal millennial laborando en sus organizaciones se relaciona con el alto nivel de rotación y ausentismo de estos jóvenes profesionales (Valdiviezo, 2014). Esta generación ha desafiado al mercado laboral; por lo tanto, es necesario que las empresas que desean retener este talento reconozcan las características, atributos, necesidades y sistemas de trabajo propios de esta generación para aprovecharlo e integrarlo en los objetivos de la organización (Karsh \& Templin, 2013, «a», cap. 5, doc. 1).

Actualmente, el tema de estrategias de fidelización laboral se ha ido investigando un poco más en el Perú; sin embargo, existe el problema de que se sigue considerando que los millennials peruanos tienen las mismas características de personalidad que los millennials norteamericanos, lo que implica que las estrategias de retención son planteadas en base a un perfil impropio del millennial peruano. Por esa razón, para tener una estrategia eficiente, es necesario primero conocer las características que definen a su público objetivo.

Esta investigación busca ser una herramienta para las organizaciones pues no solo esboza un perfil sobre el comportamiento y las características de un grupo de jóvenes millennials universitarios que no existe en la actualidad, sino que podría representar una información valiosa sobre las expectativas que este grupo de jóvenes tiene con respecto al lugar donde trabajan y las estrategias que dicho grupo prefiere que se implementen para retenerlos.

\section{Marco teórico}

\subsection{Rangos generacionales}

El término «rango generacional» hace referencia al concepto de generación, el cual es definido como "un grupo de personas segmentadas por la edad que comparten una serie de experiencias formativas que los distinguen» (Chirinos, 2009, "a», p. 137). Según Howe 
y Strauss (citado en Rodríguez \& Peláez, 2010, pp. 161-164), son tres los atributos que deben estar presentes para definir la naturaleza de una generación: la autopercepción de pertenencia, las conductas y creencias comunes, y los hechos o situaciones importantes de cambio.

Existen experiencias formativas que marcaron un hito entre cada generación poblacional; no obstante, no se puede detallar un único rango de edad para cada generación debido a que no es una única experiencia la que los une, sino un conjunto de estas, cercanas en el tiempo, pero diferentes entre sí. Por dicho motivo, el rango de edades que segmenta a cada generación es muy debatido en la actualidad (US American Chamber of Commerce, 2012, p. 2).

\subsection{La Generación Y}

La generación siguiente a la X es normalmente conocida como la Generación Y, Millennial o «The Me Me Me Generation». Nilda Chirinos señala que esta generación nació entre los años 1982 y 2000, y entre los eventos que los definieron como segmento la autora destaca la aparición de las computadoras e Internet, el calentamiento global, el boom económico de los años noventa y los ataques terroristas en diversos países (Chirinos, 2009, p. 140).

La Generación Millennial ha adoptado varios nombres y comprende, sobre todo, a los hijos de los baby boomers. Estos jóvenes crecieron en un lapso de tiempo que dio lugar a situaciones relevantes como la caída del Muro de Berlín, la recesión mundial, el ataque terrorista del 9/11, el tsunami en Asia, la Primavera Árabe, y el surgimiento de Facebook y los smartphones. Todos estos acontecimientos definen e influyen en el comportamiento de los millennials, quienes son la generación más diversa y educada en toda la historia (US American Chamber of Commerce, 2012, pp. 2-3). En los Estados Unidos equivalen a la tercera parte de la población y son un cuarto de la población mundial a nivel global (Pew Research Center, 2009, p. 9).

En esta investigación consideraremos que el millennial es aquel joven nacido entre los años 1981 y 2000, tomando como referencia la definición dada por Karsh y Templin (2013, «b»); asimismo, ese joven también debe cumplir con ciertos patrones de comportamiento comunes de grupo.

Chirinos explica que los integrantes de esta generación son idealistas y buscan la felicidad, están conectados 24 horas al día, los siete días de la semana, y son personas que saben trabajar en equipo, orientadas al logro y con pensamiento social (Chirinos, 2009, «b», p. 140). El Fondo de Pensiones de las Naciones Unidas señala que los millennials se caracterizan por ser sociables, morales, diversos, tenaces y necesitados de flexibilidad (2006, pp. 6-7).

Expertos señalan que este grupo de trabajadores más jóvenes podría tener diferentes valores relacionados con el trabajo en comparación con sus predecesores. Por ejemplo, en base a un estudio, se descubrió que los empleados mayores suelen estar más centrados en el trabajo, mientras que los empleados más jóvenes tienden a centrarse más en la familia o en ambos aspectos (Dessler \& Varela, 2004, p. 10).

En el aspecto laboral, el millennial no tolera una estructura de trabajo rígida y considera que el respeto por la autoridad debe ser ganado por los conocimientos que este 
aporta en la organización; igualmente, disfruta trabajar en equipo, es muy persistente y optimista, no tiene miedo a decir lo que piensa, quiere cambiar el mundo y busca marcar la diferencia (Karsh \& Templin, 2013, "c», cap. 1, doc. 13, § 4).

Tabla 1. Cuadro comparativo de las características generacionales

\begin{tabular}{|c|c|c|c|c|}
\hline $\mathbf{N}^{\circ}$ & Detalle & Baby Boomers & Generación X & Generación Y \\
\hline 1 & Percepción del resultado & Optimista & Pesimista & Optimista \\
\hline 2 & Estilo de trabajo & Competitivo & Competitivo & Trabajo en equipo \\
\hline 3 & Lugar preferido para laborar & Trabajo en la oficina & Trabajo en la oficina & $\begin{array}{l}\text { Trabajo en cualquier } \\
\text { lugar }\end{array}$ \\
\hline 4 & Apertura a la crítica & Rechazo al feedback & Rechazo al feedback & Necesidad de feedback \\
\hline 5 & Objetivos laborales & $\begin{array}{l}\text { Crecer dentro de una } \\
\text { organización }\end{array}$ & Emprender algo propio & Emprender algo propio \\
\hline 6 & Modo de trabajo & Una sola tarea a la vez & Una sola tarea a la vez & Multitasking \\
\hline 7 & Percepción del futuro & Idealistas & Escépticos & Idealistas \\
\hline 8 & Actitudes hacia la autoridad & Relación amor/odio & Desafían la autoridad & Respeto mutuo \\
\hline 9 & $\begin{array}{l}\text { Motivo fidelizador en la orga- } \\
\text { nización }\end{array}$ & Leales a las empresas & $\begin{array}{l}\text { Leales a los com- } \\
\text { pañeros }\end{array}$ & Leales a los beneficios \\
\hline 10 & Frase de identificación & Amo trabajar & Trabajo para sobrevivir & $\begin{array}{l}\text { Vivo primero, luego } \\
\text { trabajo }\end{array}$ \\
\hline 11 & Balance trabajo-familia & Trabajo & Trabajo & Equilibrio \\
\hline 12 & Manejo de la tecnología & Poco & Medio & Alto \\
\hline 13 & Conectividad & A veces & Frecuentemente & Siempre \\
\hline 14 & Percepción del mercado & Apegado a las reglas & Flexible a las reglas & Innovador a las reglas \\
\hline
\end{tabular}

Fuente: Dávila y Mitta (2015, p. 18).

\subsection{Gestión de la diversidad}

Para Castillo y Suso, el concepto de gestión de la diversidad «tiene sus orígenes en la década de los años ochenta, en los EE.UU.» (2012, p. 36). Este concepto es definido por Casanova como "Una estrategia destinada a potenciar e integrar la diversidad creciente de las organizaciones (diferentes razas, culturas, religiones, edades, idiomas, orientaciones sexuales) y traducirla en beneficios económicos y sociales» $(2006$, p. 1).

La gestión de la diversidad no es una estrategia que se pueda replicar de la misma manera en todas las organizaciones debido a su carácter moldeable, pues esta estrategia debe ser implementada de acuerdo a las características de los colaboradores. Para ello, el primer paso es la identificación y definición de las características diferenciales de los colaboradores, por lo cual es fundamental conocerlos y reconocer sus cualidades y las características que los hacen únicos. Una vez identificados los diversos grupos, se procede al diseño del modelo organizacional a implementar, para lo cual se deben de respetar, valorar 
y potenciar todas las cualidades diferenciales de los colaboradores, así como fomentar la tolerancia entre ellos mismos. Luego, a partir de la implementación de este modelo, se hace necesaria la etapa de control y mejora continua, en la cual se van resolviendo las dificultades que aparecen en el camino y se va incentivando cada vez más la interacción entre los colaboradores.

PwC México nos detalla que las estrategias de gestión de la diversidad cuentan con cuatro etapas de madurez. La primera, llamada "Sin consideraciones», es cuando la visión de la organización está basada en un concepto de administración central. En la segunda etapa, llamada "Entendimiento», se comparten las creencias y conductas de los colaboradores de la organización. La tercera etapa, "Aceptación y acuerdos», es cuando se determinan los límites que promueven el respeto hacia los colaboradores alineados a la cultura organizacional. Por último, en la etapa de "Despegue» se obtiene el desempeño superior mediante la interacción en todos los niveles y el trabajo de equipo dentro de la organización (2015, p. 7).

\subsection{Adversidad generacional}

El contexto de la adversidad generacional es definido por la revista académica Capital Humano como la convivencia dentro de una empresa de cinco generaciones distintas (Veteranos, Baby Boomers, Generación X, Millennials y Generación Z). Ello se debe a que "comparte[n] circunstancias temporales, experiencias, valores y modos de vida comunes que marcan su esencia vital, la forma de entender el mundo y enfrentarse al trabajo, pero también tienen una cultura, gustos, ideales y un idioma propio que da lugar a una competencia intergeneracional que puede llegar a ser tóxica» (2018, p. 46).

El órgano de investigación Observatorio Generación \& Talento (s.f., p. 11) detalla las problemáticas que han sufrido las generaciones debido a la adversidad generacional de la siguiente manera:

- Los mayores de 50 años, en general, están siendo expulsados del mercado laboral con difícil retorno; asimismo, se alarga su fecha de jubilación y no saben cómo continuar trabajando hasta entonces. En la empresa, han sido aparcados y no suelen existir planes de desarrollo ni promoción para ellos.

- La Generación X es la primera generación con mejor formación que sus antecesores, y no ha encontrado recompensa a su carrera profesional. Sus expectativas se han enfrentado a una realidad de bajos sueldos y sobreabundancia de licenciaturas.

- La Generación Y se caracteriza porque sus representantes suelen ser muy formados, emigrantes, desempleados $y$, en el caso de aquellos que trabajan, están en puestos que requieren una formación inferior a su nivel de estudios y con contratos precarios.

- La Generación Z ha crecido en el desencanto de un mundo que está en plena recesión, con un mercado laboral marcado por la precariedad y la falta de oportunidades, lo que les provoca incertidumbre y desapego. 


\subsection{Retención del talento}

Prieto (2013, «a», p. 50) señala que para lograr un equipo de trabajo efectivo y unificado es importante garantizar la atracción constante y la fidelización de los talentos de la organización.

Los atributos individuales, aquellos motivos por los cuales las personas deciden desvincularse o no de una organización, son descritos por Santacruz como la inclinación a la desvinculación dentro de una organización relacionada con el nivel de satisfacción de las recompensas en el trabajo (Santacruz, 2011, «a», p. 36). Según Kinichi y Kreitner la motivación es una variable cuya relación es positiva y de intensidad moderada con respecto a la satisfacción laboral (citado en Santacruz, 2011, «a», p. 38).

\subsection{Motivación}

La motivación es uno de los factores intrínsecos que requiere mayor atención, pues es la fuerza intrínseca impulsora que demanda importancia en cualquier ámbito de la actividad humana, y es en el trabajo donde logra la mayor preponderancia (Fernández \& Moreno, citado en Santacruz, 2011, «b», p. 52).

Con el objetivo de profundizar un poco más en el concepto de motivación, se presentan los siguientes autores:

- Frederick Herzberg propuso una teoría de la motivación en base a lo que vendrían a ser los factores de higiene y motivacionales. Sobre esas variables, «Herzberg caracterizó a los factores que crean la insatisfacción con el puesto como factores de higiene. Cuando estos factores son adecuados, la gente no estará insatisfecha; sin embargo, tampoco estará satisfecha. Para motivar a las personas en sus puestos, Herzberg sugirió la enfatización de factores motivacionales, aquellos factores que aumentan la satisfacción con el puesto» (Cantu, 2006, p. 22).

- Factores higiénicos: también denominados "factores extrínsecos», son aquellos relacionados con la insatisfacción laboral pues se localizan en el ámbito donde las personas realizan sus funciones. "Los principales factores higiénicos son: el salario, los beneficios sociales, las condiciones físicas y ambientales de trabajo, las políticas y directrices de la empresa, el clima de relaciones, el estatus y el prestigio, y la seguridad personal, etc.» (Prieto, 2013, p. 34).

- Factores motivacionales: también denominados "factores intrínsecos" son los relacionados con la satisfacción laboral. Estos factores son conocidos como aquellos que generan interés en el individuo para ser más eficiente cada día. "Los factores motivacionales involucran los sentimientos relacionados con el crecimiento y desarrollo personal, el reconocimiento profesional, las necesidades de autorrealización, la mayor responsabilidad y dependen de las tareas que el individuo realiza en su trabajo» (Prieto, 2013, p. 34). 
- Abraham Maslow propuso una teoría de motivación en base a la jerarquía de las necesidades humanas, lo que implica que el ser humano, mientras cubra sus necesidades básicas, va a adquirir nuevas necesidades, cada vez más elevadas.

A continuación, se presenta la pirámide de la jerarquía de las necesidades establecidas por Maslow (1991, citado en Cantu, 2006, pp. 21-22):

Figura 1. La pirámide de Maslow

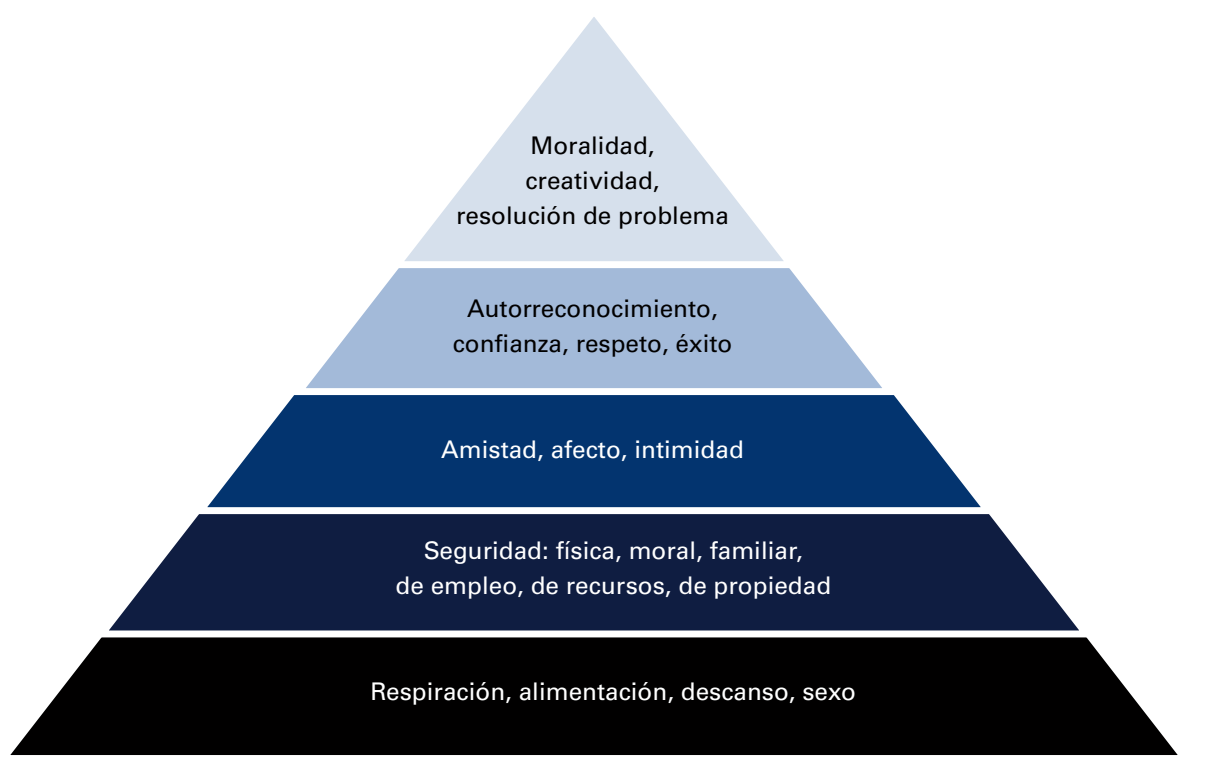

Fuente: Dávila y Mitta (2015, p. 11).

- Necesidades fisiológicas: constituyen la primera prioridad del individuo y se encuentran relacionadas con su supervivencia. Son esenciales para la vida de la persona.

- Necesidades de seguridad: «Busca la creación y mantenimiento de un estado de orden y seguridad. [...] Estas necesidades se relacionan con el temor de los individuos a perder el control de su vida y están íntimamente ligadas al miedo, miedo a lo desconocido, a la anarquía» (Cantu, 2006, p. 21).

- Necesidades de afiliación: también conocidas como necesidades sociales, están en el medio de la pirámide debido a que serán las que cumplan el rol de generar la motivación una vez que las primeras dos necesidades estén satisfechas. "Éstas tienen relación con la necesidad de compañía del ser humano, con su aspecto afectivo y su participación social. Dentro de estas necesidades tenemos la de comunicarse con otras personas, la de establecer amistad con ellas, la de manifestar y recibir afecto, la de vivir en comunidad, la de pertenecer a un grupo y sentirse aceptado dentro de él» (Cantu, 2006, p. 22).

- Necesidades de reconocimiento: "Conocidas como las necesidades del ego o de la autoestima. Este grupo radica en la necesidad de toda 
persona de sentirse apreciado [sic], tener prestigio y destacar dentro de su grupo social, de igual manera se incluyen la auto valoración y el respeto a sí mismo» (Cantu, 2006, p. 22).

- Necesidades de autorrealización: ubicada en la cima de la pirámide, esta necesidad es el punto máximo pues representa el ideal que toda persona desea alcanzar. «En este nivel el ser humano requiere trascender, dejar huella, realizar su propia obra, desarrollar su talento al máximo» (Cantu, 2006, p. 21)

- Victor Vroom señala en su teoría que «la motivación es producto del valor que un individuo le atribuye anticipadamente a una meta y la posibilidad de que se cumpla» (Cantu, 2006, "a», p. 23). Con esto quiere decir que la intensidad motivacional se dará en base a las expectativas de que se cumpla una acción y a la importancia o valor que se le atribuya a la misma.

- Thomas Davenport señala en su teoría que "las personas en una empresa son inversores en un negocio en el que brindan su capital humano y esperan conseguir un beneficio» (Prieto, 2013, «b», p. 36). De esto podemos inferir que la motivación se basa en la voluntad de la empresa y el trabajador por generar beneficios mutuos.

\subsection{Estrategias de retención}

Para poder retener el talento se debe de brindar una serie de recompensas que permita que los colaboradores se sientan a gusto con la organización y genere en ellos una correcta fidelización.

- Los beneficios sociales y el medio laboral: para Conrado los beneficios sociales permiten a la empresa crear un valor adicional $y$, dependiendo del impacto, puede darse que un colaborador no quiera desprenderse de la organización (2009, «a», pp. 42-43).

- Identificar las necesidades y las fortalezas de los empleados: "Las organizaciones deben tener conocimiento de qué necesitan sus trabajadores, qué les haría estar más satisfechos y cómo se les puede retener mejor» (Castillo, 2009, «a», p. 44).

- Incentivos económicos: Prieto señala que "Aún y cuando en estos tiempos de crisis el ingreso es sumamente importante para los empleados, [...] los empleados valoran cada vez más los beneficios no monetarios» (Prieto, 2013, "C», p. 46).

- Desarrollo personal y profesional de los empleados: Castillo señala que «la formación continua es tan importante porque no solo sirve como herramienta de motivación y retención del talento humano, sino que también reduce los fallos profesionales» (2009, «b», p. 48).

- Flexibilidad según la naturaleza del trabajo: la flexibilidad se ha convertido en un factor clave en la retención del capital humano; en ese sentido, algunas reglas sociales deben de flexibilizarse dentro de la compañía (Castillo, 2009, "C», p. 51). 
- El reconocimiento del desempeño de los colaboradores: se debe tener como "un DEBER el hecho de dar siempre reconocimiento a las personas por sus buenas intenciones y acciones ya que con esto se motiva e incentiva a que sigan comportándose de esa forma y mejorando sus procesos» (Prieto, 2013, «d», p. 44). Por otro lado, no solo es reconocer y exaltar los aciertos de los colaboradores, sino también analizar los errores cometidos a través de un feedback o retorno de información de aquello que se ha fallado.

- La promoción interna: el personal de una organización que ve en ella las oportunidades para su realización personal desarrolla un sentido de pertenencia y la necesidad de hacer siempre las cosas de la mejor manera para mantener la aptitud y ascender profesionalmente (Prieto, 2013, «e», p. 43).

\subsection{Estrategias de retención aplicadas a millennials}

Los millennials son una nueva generación y muchos autores alegan que en pocos años se convertirán en la fuerza laboral predominante alrededor del mundo. Esta Generación Millennial rompe esquemas y características de generaciones antecesoras y, por ende, no puede ser gestionada de la misma manera: estos jóvenes deben ser inspirados a través del liderazgo adecuado.

A continuación, desarrollaremos algunas estrategias sugeridas por Karsh y Templin (2013, «d», cap. 1, docs. 1-13) y la consultora PwC (2011, «a», pp. 23-25) para que la organización se convierta en atractiva para los millennials:

- Ayudarlos a crecer. Los millennials buscan aprender y crecer. Es preciso colocarlos en rotación de tareas para que estos jóvenes puedan ir aprendiendo y ganando experiencia en diversos campos; de esa forma, el trabajo no será aburrido ni rutinario.

- Poner en su conocimiento que se está haciendo. Esta generación valora las opiniones. Los millennials quieren y necesitan una retroalimentación en tiempo real, resaltando así las contribuciones positivas y el mejoramiento en las competencias claves.

- Dejarlos ser: flexibilidad laboral. Ellos saben cuáles son sus tareas a cumplir y para cuándo estas deben estar listas. Es conveniente darles la libertad de tener horarios flexibles y preocuparse más por la calidad de la tarea entregada.

- Escucha sus opiniones. Los millennials buscan que su jefe tenga una actitud «paternal» y que sepa escuchar, valorar, corregir y enseñar las tareas.

- Brindar el balance entre lo laboral y personal. Los millennials son trabajadores, aman los retos y el aprender día a día; sin embargo, no planean trabajar más allá de su horario debido a que el hogar, la familia y los amigos son importantes para ellos.

- Motivarlos constantemente. Estos jóvenes cree que pueden hacer todo lo que se proponen, tiene una can-do attitude. Los millennials necesitan encontrarle sentido a su trabajo diario y buscan identificar cómo este contribuye con la empresa. 
- Trabaja siempre en equipo. Los millennials no se identifican como líderes, para ellos cada uno es parte del grupo y aporta ideas. Asimismo, las reacciones o participaciones del equipo se deben a las actitudes de todos.

- Ambiente entretenido. Es favorable innovar en infraestructura para crear ambientes amigables y agradables donde sus empleados puedan recrearse.

- Permitir un crecimiento de línea de carrera más rápido. Los millennials valoran los resultados y muchas veces se sienten frustrados por la cantidad de tiempo que toma ascender, aun considerando el buen desempeño y resultado de su trabajo.

\section{Metodología}

El procedimiento de desarrollo de esta investigación está basado en cuatro etapas. La primera etapa es la recolección de documentación, tanto física como virtual. La segunda etapa es el análisis y adaptación de información, en la cual se priorizaron las investigaciones latinoamericanas debido a su similitud con el país objetivo, que es Perú. La tercera etapa es la recolección de nueva información mediante técnicas cualitativas y cuantitativas: entrevistas semiestructuradas a expertos locales y encuestas a la muestra poblacional. Finalmente, la cuarta etapa es el análisis y comparación de la información local con la información latinoamericana.

Para poder llevar a cabo esta investigación se han definido tres hipótesis de estudio para su respectiva puesta a prueba:

- Primera hipótesis. Existen características del comportamiento del grupo de jóvenes millennials encuestados que son similares a los descritos para los estadounidenses.

- Segunda hipótesis. El grupo de jóvenes millennials universitarios encuestados tiene expectativas laborales diferentes a las señaladas en la teoría.

- Tercera hipótesis. Un grupo de organizaciones limeñas no solo tiene conocimientos acerca de lo que es la Generación Millennial y sus expectativas, sino que también buscan fidelizarlos mediante políticas y prácticas de retención.

En esta investigación se aplicó un enfoque mixto y una metodología exploratoria debido a que el objetivo principal es investigar un tema que ha sido poco estudiado en nuestro país; asimismo, hemos podido identificar ciertos rasgos de la metodología descriptiva y correlacional. Descriptiva porque nos permite detallar las características y preferencias del grupo de jóvenes encuestados y, a su vez, las opiniones de encargados de las áreas de recursos humanos de un grupo de organizaciones seleccionadas; y correlacional porque se ha podido evaluar la relación entre diversas variables, como los datos obtenidos mediante encuestas y entrevistas. Es necesario resaltar la limitación que presenta esta investigación, pues no se pueden generalizar los resultados por el tamaño de la muestra.

La encuesta se aplicó a un grupo de jóvenes de entre 18 y 26 años de la Pontificia Universidad Católica del Perú que cursaban los últimos ciclos de las carreras Gestión, 
Economía e Ingeniería Industrial. Se consideró pertinente encuestar a alumnos que se encuentren cursando el noveno y décimo ciclo de la carrera debido a que un estudiante con experiencia laboral responderá la encuesta en base de sus experiencias de trabajo y no únicamente apelando a sus expectativas, lo que asegura una valoración más realista sobre los factores clave que motivan a los miembros de esta generación a ser "fidelizados".

Para el caso de esta investigación se ha realizado un muestreo por conglomerados. Dicho muestreo se segmentó de manera estratificada porque se buscó la representatividad de las poblaciones de las tres carreras estudiadas; de esa manera, la carrera de Gestión fue representada por un 37\%, Ingeniería Industrial por un 35\% y Economía por un $28 \%$ del universo encuestado.

Al momento de la realización de la encuesta, las carreras de Economía, Gestión e Ingeniería Industrial contaban con 208, 306 y 291 alumnos de últimos ciclos, respectivamente. Este conjunto de alumnos representa el universo del cual se buscará obtener una muestra representativa poblacional finita. La muestra será calculada teniendo en cuenta una heterogeneidad del universo del 50\%, un margen de error de +/- 5 y un nivel de confianza del $90 \%$ para obtener una fiabilidad de la muestra de alto nivel. Se realizaron 264 encuestas, de las cuales 237 fueron válidas y 27 inválidas. Cabe señalar que se consideraron encuestas inválidas aquellas desarrolladas por encuestados que no habían realizado prácticas laborales.

Los sujetos de investigación cualitativa son las empresas que aplican estrategias de talento y a las cuales van orientadas las estrategias de diversidad. Entre ellas se encuentran los grupos segmentados de acuerdo a su rango generacional para recolectar, validar y analizar los datos, objetivo para el que se implementaron técnicas de obtención de fuentes secundarias - lo que implica una exhaustiva revisión de documentos físicos y virtuales-y técnicas de recolección de información primaria como las entrevistas semiestructuradas a expertos. Dichas entrevistas se basan en un guion de preguntas ya establecidas y enfocadas en responder nuestras hipótesis; pero, asimismo, son de carácter abierto, ya que muchas preguntas favorecen la oportunidad de recibir más matices de respuesta (Hernández, Fernández \& Baptista, 2010, p. 148). Las organizaciones entrevistadas se agruparon en dos grupos: sector público (conformado por: Produce, Osiptel, BCRP y un experto que solicitó la anonimidad del nombre de la organización) y sector privado (Interoc S.A., Carter S.A., Laborum S.A.C, Comersia S.A., Clínica Internacional S.A.C. y GMD S.A.C.).

\section{Análisis descriptivo}

A continuación, se describirán los resultados de las encuestas y las entrevistas realizadas.

\subsection{Análisis estadístico de las encuestas}

La información demográfica del grupo encuestado está graficada en el anexo 1.

\subsection{Características del comportamiento}

En el anexo 2 se presenta el compilado de los resultados de la encuesta aplicada. En el extremo izquierdo se han ubicado las características del perfil millennial norteamericano, 
las cuales se han resaltado de color rojo (ver anexo 2). Así, se procederá a detallar los resultados en tres categorías: las características similares, las características divididas y las características diferentes.

- Características similares: las características similares a las descritas en el perfil del millennial norteamericano reflejadas en el comportamiento de estos jóvenes fueron las siguientes:

- "Apertura a la crítica»: el 92.83\% siente necesidad de retroalimentación.

- «Manejo del tiempo»: el $82.70 \%$ busca el equilibrio entre el trabajo y la familia.

- "Estilo de trabajo»: el $80.17 \%$ de los participantes se considera colaboracionista.

- "Modo de trabajo»: el 74.68\% de los participantes realiza varias tareas a la vez.

- «Lugar preferido para laborar»: el 70.04\% terminaría sus pendientes en cualquier lugar.

- Características divididas: las características divididas son aquellas que no son opuestas al perfil del millennial norteamericano, pero tampoco son significantemente distintas. Estas son:

- "Motivos de permanencia»: el 67.09\% permanecía de acuerdo a los beneficios; sin embargo, el 18\% permanecía leal a los compañeros y el $15 \%$ leal a la organización.

- «Fase de identificación»: el 58.23\% respondió que prefería vivir primero y luego trabajar, mientras que un $23 \%$ señaló que trabajaban para sobrevivir y un $19 \%$ que amaban trabajar.

- "Objetivos laborales»: un 52.74\% de los encuestados desean emprender su propia organización, mientras que un $47 \%$ desea crecer en una organización.

- Características diferentes: las características diferentes a las descritas en el perfil del millennia/ norteamericano reflejadas en el comportamiento de estos jóvenes fueron los siguientes:

- «Manejo del dinero»: el 43.04\% cumplió con el perfil norteamericano como ahorradores; sin embargo, un 53\% tienen una actitud derrochadora.

- «Percepción del proceso»: el 42\% cumple con el perfil norteamericano al demostrar una postura innovadora de reglas, mientras que un $43 \%$ señala que su postura es más flexible que innovadora. Asimismo, un $15 \%$ optó por apegarse a las reglas.

- "Postura frente al futuro»: el 20.68\% cumplió con el perfil al describirse como idealistas; sin embargo, un $75 \%$ de los participantes se considera realistas.

A modo de conclusión, podemos resumir que el grupo de jóvenes universitarios encuestado, considerados como millennials por el rango de edad en el que se encuentran, presenta una coincidencia de $65.85 \%$ con el perfil del millennial norteamericano. 
Adicionalmente, hay que señalar que las características más resaltantes del universo de encuestados fueron el optimismo, que alcanzó un 94.94\% de congruencia con el perfil norteamericano, y el realismo, que si bien no va acorde con el perfil con el que se ha contrastado, aun así llegó a un 75\% de participantes.

\subsubsection{Resultados de motivos de fidelización de los participantes}

Con el objetivo de medir la importancia de cada alternativa, se le brindaron pesos a cada puesto ocupado.

Tabla 2. Pesos y ponderaciones de motivos para «fidelizar»

\begin{tabular}{|c|c|c|c|c|c|c|c|c|}
\hline & & Pesos & 2 & 1.75 & 1.5 & 1.25 & 1 & \\
\hline & Opción & Código & Preg. 1 & Preg. 2 & Preg. 3 & Preg. 4 & Preg. 5 & $\begin{array}{l}\text { Total } \\
\text { pond. }\end{array}$ \\
\hline 1 & Desarrollo personal y profesional & DES & $\underline{89}$ & 45 & 29 & 17 & 14 & $\underline{335.5}$ \\
\hline 2 & Salario e incentivos económicos & SAL & 64 & 43 & 36 & 22 & 29 & 313.8 \\
\hline 3 & Prestigio de la organización & PRE & 13 & 44 & 41 & 41 & 13 & 228.8 \\
\hline 4 & Equilibrio trabajo-familia & FLE & 26 & 15 & 21 & 32 & 27 & 176.8 \\
\hline 5 & $\begin{array}{l}\text { Posibilidad de crecimiento en la } \\
\text { organización }\end{array}$ & CRE & 10 & 25 & 20 & 26 & 29 & 155.3 \\
\hline 6 & Reconocimiento del desempeño & REC & 5 & 20 & 25 & 18 & 46 & 151 \\
\hline 7 & $\begin{array}{l}\text { Objetivos de la empresa simi- } \\
\text { lares a los míos }\end{array}$ & OBJ & 4 & 19 & 23 & 36 & 19 & 139.8 \\
\hline 8 & $\begin{array}{l}\text { Relación fluida con los super- } \\
\text { visores }\end{array}$ & REL & 19 & 11 & 11 & 14 & 25 & 116.3 \\
\hline 9 & Trabajo en equipo & T. EQ & 2 & 6 & 7 & 13 & 8 & 49.3 \\
\hline 10 & Estabilidad laboral & EST & 3 & 2 & 8 & 7 & 16 & 46.3 \\
\hline 11 & Trabajo como reto personal & RET & 2 & 7 & 9 & 6 & 6 & 43.3 \\
\hline 12 & Celebración de actividades & ACT & 0 & 0 & 7 & 5 & 5 & 21.8 \\
\hline
\end{tabular}

La ponderación de cada alternativa se ve afectada dependiendo del puesto que ocupe, si una alternativa quedaba en el puesto 1 se le otorgó un peso de 2 puntos, si quedaba en el puesto 2 se le otorgó un puntaje de 1.75, sucesivamente. Se analizaron todas las alternativas y se pudo obtener las ponderaciones de los puntajes correspondientes a cada motivo de fidelización. 


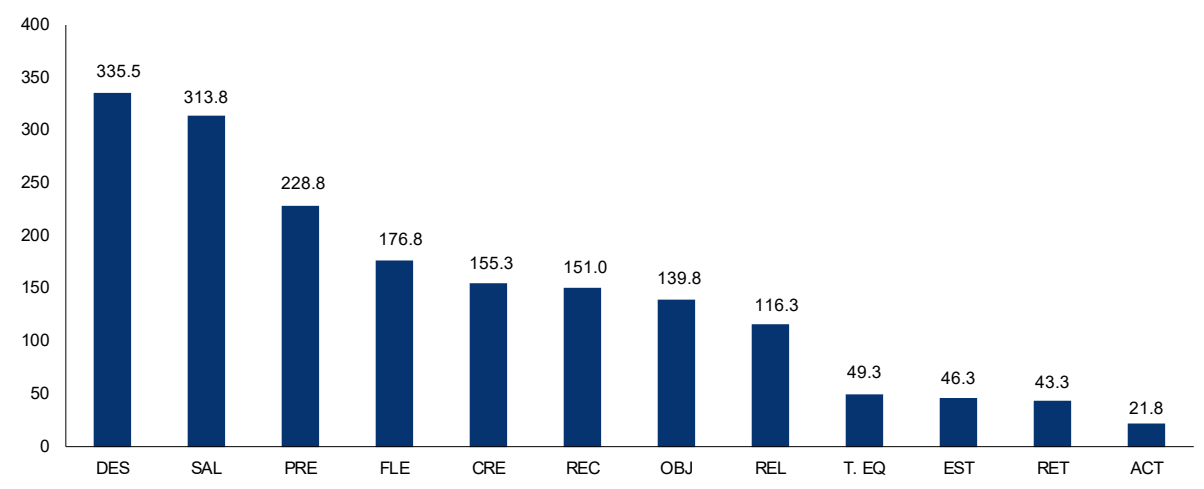

Fuente: Dávila y Mitta (2015, p. 77).

Los motivos más importantes reflejan que para que el grupo encuestado sea fiel a una organización es importante incentivar el aprendizaje que obtienen, el nivel de ingresos que le ofrecen, el prestigio de la organización, la flexibilidad laboral brindada y, por último, la posibilidad de crecimiento en la organización.

Se observa un detalle bastante relevante, que son los motivos de fidelización menos elegidos. Los cinco primeros son la celebración de actividades como cumpleaños y aniversarios, el reto profesional que significa trabajar en la organización, la sensación de seguridad, la sensación de protección brindada (estabilidad laboral) y la frecuencia del trabajo en equipo.

\subsubsection{Resultados de preferencias de políticas de retención de los participantes}

Con el objetivo de medir la importancia de cada alternativa, se le brindó pesos a cada puesto ocupado.

Tabla 3. Pesos y ponderaciones de preferencias en estrategias de retención de personal

\begin{tabular}{ll|l|l|l|l|l|l|l} 
& & Pesos & $\mathbf{2}$ & $\mathbf{1 . 7 5}$ & $\mathbf{1 . 5}$ & $\mathbf{1 . 2 5}$ & $\mathbf{1}$ & \\
\hline \multicolumn{1}{c}{ Opción } & Código & Preg 1 & Preg 2 & Preg 3 & Preg 4 & Preg 5 & $\begin{array}{l}\text { Total } \\
\text { pond. }\end{array}$ \\
\hline $1 \quad$ Brindar línea de carrera & LIN. C & 67 & 48 & 28 & 16 & 17 & 297 \\
\hline 2 & $\begin{array}{l}\text { Retroalimentación constante } \\
\text { sobre el desempeño }\end{array}$ & RETR & 36 & 34 & 32 & 18 & 30 & 232 \\
\hline $3 \quad \begin{array}{l}\text { Flexibilidad en cumplimiento de } \\
\text { tareas }\end{array}$ & FLEX & 16 & 30 & 37 & 17 & 15 & 176.3 \\
\hline $4 \quad$\begin{tabular}{l} 
Bonos salariales \\
\hline 5
\end{tabular}$\quad \begin{array}{l}\text { Rotación de tareas para generar } \\
\text { mayor aprendizaje }\end{array}$ & ROT & 27 & 11 & 11 & 34 & 31 & 163.3 \\
\hline $6 \quad$ Brindar capacitaciones y cursos & CAP & 20 & 29 & 21 & 8 & 16 & 148.3 \\
\hline
\end{tabular}




\begin{tabular}{ll|l|l|l|l|l|l|l}
\hline 7 & Actividades que liberen el estrés & ACT & 11 & 8 & 20 & 19 & 9 & 98.8 \\
\hline 8 & $\begin{array}{l}\text { Trabajar siempre en equipo, } \\
\text { enfatizar el compañerismo, la } \\
\text { colaboración y la relación entre } \\
\text { ellos }\end{array}$ & COMP & 8 & 14 & 11 & 17 & 16 & 94.3 \\
\hline $9 \quad \begin{array}{l}\text { Autonomía en la forma de } \\
\text { desarrollar las tareas }\end{array}$ & AUT & 9 & 18 & 7 & 11 & 16 & 89.8 \\
\hline $10 \quad \begin{array}{l}\text { Brindarles un ambiente entre- } \\
\text { tenido, buscando incentivar la } \\
\text { innovación, la creatividad y el } \\
\text { trabajo en equipo }\end{array}$ & AMB & 3 & 14 & 9 & 17 & 17 & 82.3 \\
\hline 11 & $\begin{array}{l}\text { Informar la importancia de los } \\
\text { colaboradores en la organización }\end{array}$ & INF & 8 & 8 & 8 & 13 & 4 & 62.3 \\
\hline 12 & $\begin{array}{l}\text { Disminuir rotación de personal } \\
\text { para no desmotivar }\end{array}$ & R. & 2 & 1 & 7 & 20 & 19 & 60.3 \\
\hline $13 \quad \begin{array}{l}\text { Aprovechamiento de las habili- } \\
\text { dades tecnológicas }\end{array}$ & DISP & 6 & 10 & 8 & 5 & 7 & 54.8 \\
\hline 14 & $\begin{array}{l}\text { Escuchar sus opiniones, fomen- } \\
\text { tar el trato jefe-colaborador }\end{array}$ & OPI & 6 & 2 & 15 & 4 & 4 & 47 \\
\hline
\end{tabular}

Fuente: Dávila y Mitta (2015, p. 78).

Con el objetivo de medir la importancia de cada alternativa se le brindaron pesos a cada puesto ocupado, si una alternativa quedaba en el puesto 1 se le otorgó un peso de 2 puntos, si quedaba en el puesto 2 se le otorgó un puntaje de 1.75, y así sucesivamente. Se analizaron todas las alternativas y se pudo obtener las ponderaciones de los puntajes correspondientes a cada preferencia en estrategias de retención de personal.

Figura 3. Resultados de las estrategias de retención de personal

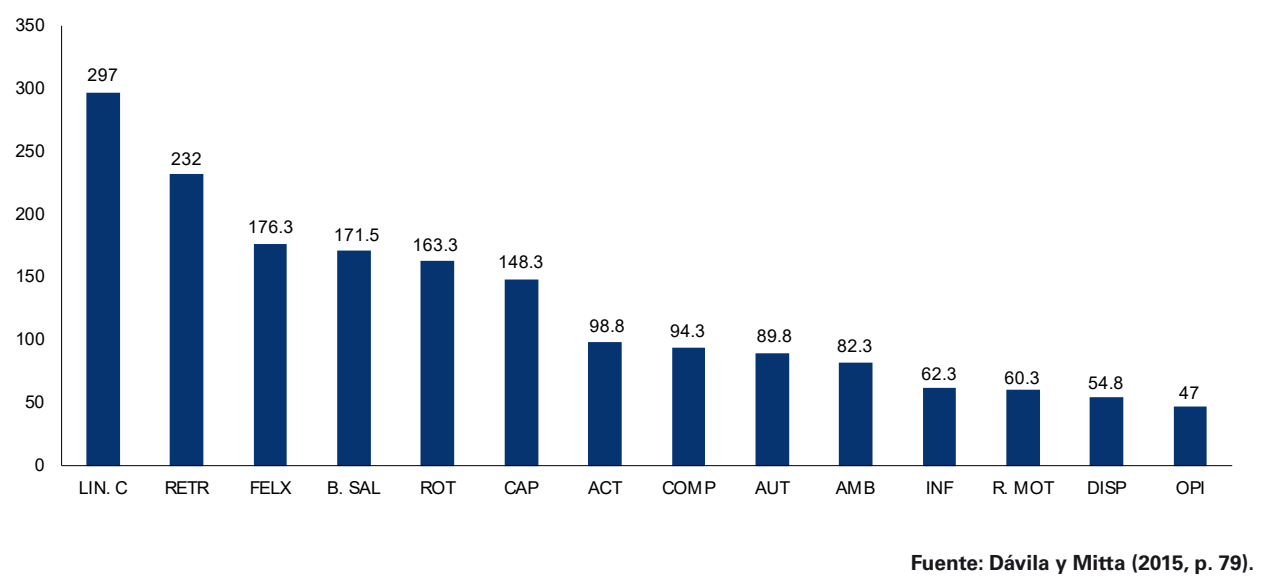

Las cinco estrategias más importantes de acuerdo a los pesos ponderados son brindar el conocimiento de la línea de carrera, brindar retroalimentación constante con conocimientos de su desempeño, dar flexibilidad con el cumplimiento de las tareas, brindar bonos salariales dependiendo de la productividad y darle rotación a las tareas de los jóvenes para generar nuevas experiencias y aprendizajes. 
Se observan también las estrategias de retención menos elegidas. Las cinco primeras son escuchar las opiniones del colaborador, valorar sus habilidades específicas, valorar las dependencias tecnológicas del colaborador, disminuir la rotación del personal y comunicar a los colaboradores la importancia de los mismos dentro del centro de trabajo.

\subsection{Análisis de las entrevistas}

Cabe resaltar que en las entrevistas se consideró que las políticas y prácticas de retención son orientadas tanto a los colaboradores que están bajo la modalidad de prácticas preprofesionales y profesionales como a los que se encuentran en planilla. Asimismo, se consideró que la rotación de estas organizaciones incluía a ambos segmentos y la inversión en estrategias de retención no es estratificada.

La entrevista se dividió en dos módulos, los cuales se subdividieron en cinco variables. El módulo de "gestión de recursos humanos" abarca las variables área de recursos humanos, rotación de personal e inversión en el área; mientras que el módulo "gestión del personal millennial» se dividió en las variables personal millennial y políticas de retención. A continuación, se detallará el análisis de estas variables.

- Variable: área de recursos humanos. De las organizaciones estudiadas, casi todas manifestaron su preocupación por «fidelizar» al colaborador. Las actividades principales que realizan este grupo de áreas de recursos humanos son bastante similares, ya que se enfocan en actividades de bienestar para el colaborador.

- Variable: personal millennial. Todo este grupo de organizaciones seleccionadas contestó que sí tenía conocimiento sobre la Generación Millennial o Generación Y. Además, el perfil descrito de los millennial fue similar en todas las organizaciones: jóvenes tecnológicos, que están siempre a la vanguardia, multitasking, con capacidades y habilidades múltiples, siempre conectados a las redes sociales, proactivos, optimistas, colaboradores y que gustan de aprender y trabajar en equipo. Todas las organizaciones afirmaron que existen millennials laborando en sus instituciones y que equivalen aproximadamente al $27 \%$ de la fuerza laboral.

- Variable: políticas de retención. Los resultados demostraron que nueve de las diez organizaciones entrevistadas afirmó que las políticas de recursos humanos no han variado a pesar de tener como parte de su fuerza laboral a los millennials. Siete de las diez áreas de recursos humanos creen que se deberían implementar nuevas políticas que estén dirigidas a esta generación.

A modo de conclusión, se observa que los responsables de las áreas de recursos humanos del grupo de organizaciones entrevistadas tienen conocimiento sobre la Generación Millennial; sin embargo, no han aplicado políticas nuevas que estén dirigidas a fidelizar y retener a esos colaboradores. 


\section{Análisis inferencial}

El presente estudio presenta rasgos correlaciones, los cuales se verán reflejados a continuación mediante la interpretación y comparación de las variables estudiadas.

\subsection{Comparación entre resultados de la encuesta y el perfil del millennial norteamericano}

La primera relación estudiada se da entre los resultados de la encuesta aplicada a jóvenes millennials universitarios anteriormente definidos y las características del perfil del millennial norteamericano:

- Categoría laboral. Con respecto a los objetivos laborales, y según el perfil del millennial norteamericano, los millennials se caracterizan por ser emprendedores; no obstante, los resultados de esta encuesta revelaron que solo el $52.74 \%$ se identifica con esta opción, ya que el resto $(47.26 \%)$ señaló que quería crecer dentro de una organización. Por último, en la postura con respecto a las reglas, los jóvenes millennials encuestados consideran que son flexibles a las reglas en un $43 \%$ de los casos, mientras que la teoría norteamericana sobre millennials considera que estos son innovadores con las reglas. En esta encuesta, solo el $42.19 \%$ de los encuestados se consideró innovador con las reglas.

- Categoría personal. La frase de vida con la que se identifican los millennials norteamericanos es «Vivir primero, luego trabajar». Esta fue escogida como respuesta por el 58.23\% de jóvenes millennials universitarios encuestados, el resto de jóvenes se identificó con frases como "Trabajar para sobrevivir» $(23 \%)$ y «Amo trabajar» (19\%).

- Categoría tecnológica. Con respecto al manejo de la tecnología por parte de los millennials, estos tienen alto conocimiento de la misma, de acuerdo a la definición norteamericana; sin embargo, en los resultados locales solo el $52.74 \%$ consideró esta opción, mientras que el $27 \%$ eligió la opción nivel medio y el $20 \%$ el nivel bajo.

Recapitulando, de esta comparación se observa que los jóvenes millennials encuestados tienen características y comportamientos similares a los que presenta el perfil del millennial norteamericano en un $65.85 \%$. Estos resultados de la encuesta demuestran que si bien el grupo de jóvenes encuestados debería ser considerado como millennial por el rango de edad en el que se encuentra, este manifiesta comportamientos diferentes a los planteados en el perfil del millennial norteamericano, algo que puede deberse a los acontecimientos ocurridos durante su formación. Siguiendo a Cuesta, Ibáñez, Tagliabue y Zangaro (2009, p. 129), "[...] es necesario encontrar cuáles son los eventos que "moldean" la construcción de los valores y paradigmas de la nueva generación [...] estos eventos significativos generacionales son los que impactan en la forma de entender la realidad, y por lo tanto, en los comportamientos de los miembros de una generación». 
Por otro lado, si bien es cierto que durante los años ochenta e inicios de los noventa el país sufrió una gran crisis económica, la mayoría de los jóvenes millennials, poco antes de cumplir la mayoría de edad, vieron cómo progresivamente el país comenzaba a tener políticas económicas estables, lo cual le permitió ser parte de la economía global, atraer la inversión privada y, por ende, incrementar la generación de empleos. Por el contrario, "[...] los Millennials norteamericanos desarrollaron un espíritu emprendedor porque fueron testigos de una inestabilidad laboral y la reducción de trabajo de sus padres después de años de lealtad de servicio [...] las condiciones del mercado y la tasa de desempleo dirigieron a muchos jóvenes a convertirse en emprendedores" (US American Chamber of Commerce, 2012, p. 11).

5.2. Comparación entre el perfil resultado de las encuestas y la percepción del millennial de un grupo de áreas de RR. $\mathrm{HH}$.

La segunda relación estudiada se da entre la información adquirida de las características de los jóvenes millennials encuestados (ver anexo 2) y las entrevistas aplicadas a los encargados del área de recursos humanos de un grupo de organizaciones seleccionadas.

Figura 4. Percepción sobre millennials por parte de los encargados de las áreas de recursos humanos del grupo de organizaciones entrevistadas

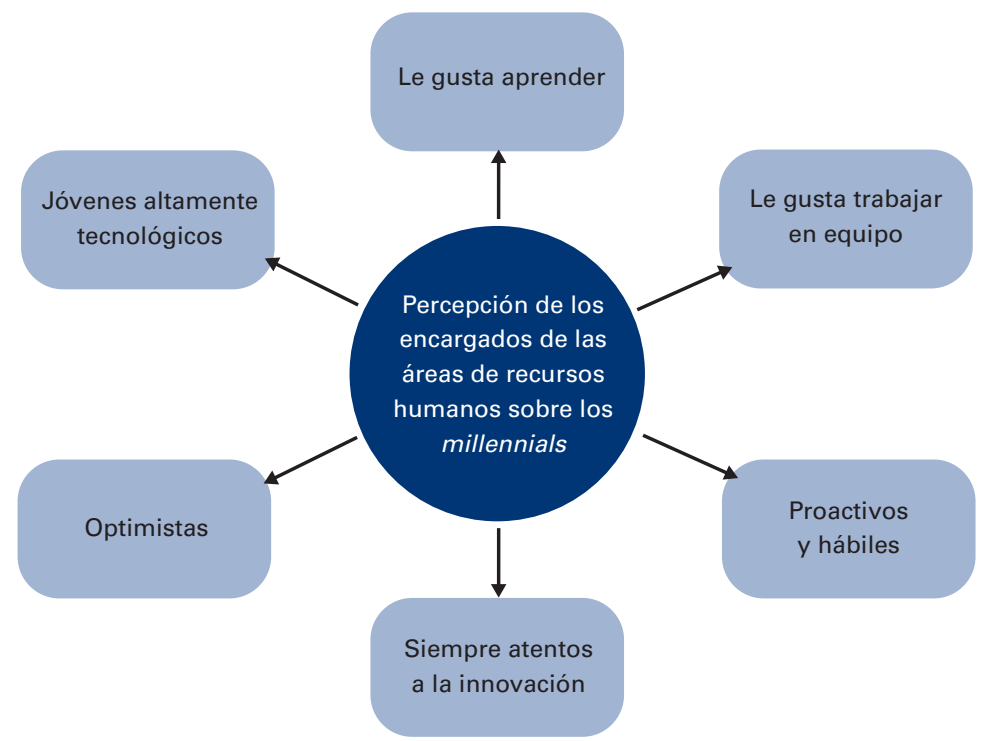

Fuente: Dávila y Mitta (2015, p. 87).

Al grupo de encargados de recursos humanos de las organizaciones estudiadas se le preguntó sobre los millennials y la importancia de estos en sus organizaciones. Como respuesta obtuvimos que todas las organizaciones habían escuchado hablar sobre esta generación y que la presencia de esta generación como fuerza laboral en estas organizaciones es del $30 \%$. 
Se puede observar que los encargados del área de recursos humanos del grupo de organizaciones estudiadas perciben que existe una similitud entre las características que señala el perfil de los millennials norteamericanos y las características de los millennials locales. Estas similitudes son las siguientes: jóvenes optimistas, a quienes les gusta trabajar en equipo, que buscan equilibrio entre la vida personal (familia) y el trabajo, que hacen muchas cosas a la vez de manera natural y que disfrutan aprender.

Existen algunas características que no fueron percibidas por los entrevistados; sin embargo, eso no significa que los jóvenes colaboradores considerados como millennials no las posean, sino que puede que estas no sean tan predominantes como en la definición del perfil millennial norteamericano. Asimismo, esto nos hace notar la importancia de que las áreas de recursos humanos conozcan a fondo los gustos y requerimientos de esta generación, y que las políticas de motivación y retención sean más integrales a todos sus colaboradores.

\subsection{Análisis entre los deseos de fidelización y las teorías de motivación}

El presente análisis evalúa la relación entre los "deseos de fidelización» obtenidos como respuesta en la encuesta aplicada y la información obtenida del marco teórico acerca de la motivación de las personas.

Figura 5. Resultado de opciones de motivación (encuesta)

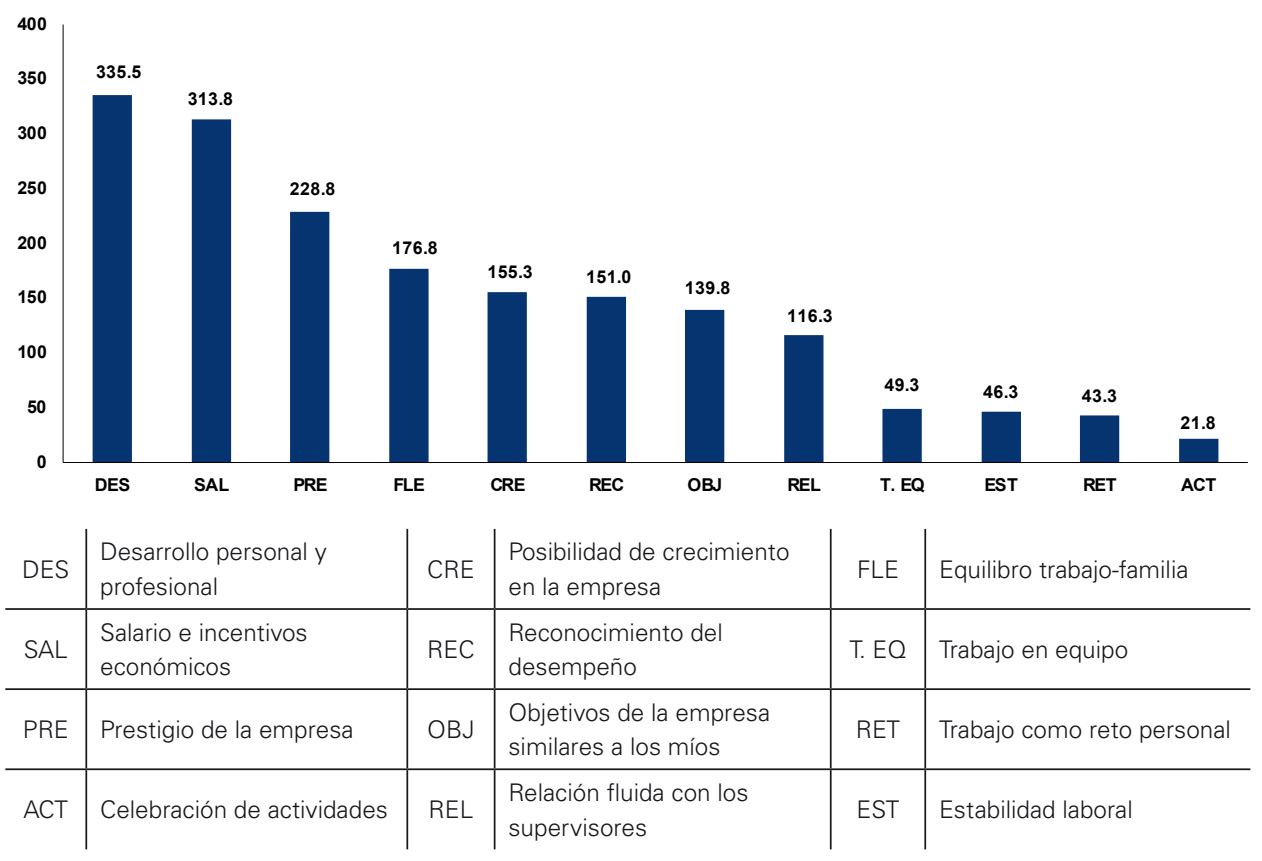

Fuente: Dávila y Mitta (2015, p. 88).

La cartilla fue construida a partir de los motivos de fidelización explicados en el marco teórico. Los resultados de esta demuestran que de las cinco más votadas, tres de 
ellas son respuestas al cubrimiento de factores higiénicos (extrínsecos) y las restantes a factores motivacionales (intrínsecos), según la teoría de Herzberg; o, según la teoría de Maslow, necesidades de afiliación y autorrealización, respectivamente.

Dentro de los factores higiénicos o extrínsecos de Herzberg encontramos «el salario, los beneficios sociales, el tipo de dirección o supervisión que las personas reciben de sus superiores, las condiciones físicas y ambientales de trabajo, las políticas y directrices de la empresa, el clima de relaciones entre la empresa y las personas que en ella trabajan, los reglamentos internos, el estatus y el prestigio, y la seguridad personal, etc.» (Prieto, 2013, «f», p. 34). Dentro de los factores motivacionales o intrínsecos de Herzberg también están los sentimientos relacionados con «el crecimiento y desarrollo personal, el reconocimiento profesional, las necesidades de autorrealización, la mayor responsabilidad y dependen de las tareas que el individuo realiza en su trabajo» (Prieto, 2013, "f», p. 34). En otras palabras, los jóvenes encuestados responden de manera más positiva a la aplicación de factores mixtos (extrínsecos e intrínsecos), mientras que el perfil del millennial norteamericano responde al cubrimiento de factores intrínsecos.

Por otro lado, dentro de los cinco más votados, se estaría haciendo referencia al cubrimiento de las necesidades fisiológicas, de autorrealización, de afiliación y de reconocimiento de Abraham Maslow. Entre las necesidades fisiológicas encontramos al salario, y entre las necesidades de reconocimiento está el deseo de toda persona de sentirse apreciado, tener prestigio y destacar dentro de su grupo social, la autovaloración y el respeto a sí mismo. Por otro lado, dentro de las necesidades de autorrealización está la sensación de desarrollar su talento al máximo y, finalmente, dentro de las necesidades de afiliación, está la relación del ser humano con respecto a los demás y a la compañía (Cantu, 2006, «b», p. 22). En este caso, vemos que las opciones más votadas representan un mix de las necesidades detalladas por Maslow.

Generalmente, las organizaciones han venido haciendo énfasis en la aplicación de factores extrínsecos como el salario y los beneficios sociales, ya que estos han sido atractivos para grupos de otras generaciones como los baby boomers y xers; no obstante, bajo el perfil del millennial norteamericano, los jóvenes preferirían factores motivacionales intrínsecos, como se señala en las estrategias de retención aplicadas para los millennials en el marco teórico. A pesar de ello, el grupo de jóvenes encuestados muestra una preferencia de retención mediante cubrimiento de factores mixtos (intrínsecos y extrínsecos). Con respecto a las teorías de Maslow, los jóvenes universitarios encuestados y el perfil del millennial norteamericano tienden a preferir el cubrimiento de necesidades fisiológicas, de afiliación, de autorrealización y de reconocimiento.

\subsection{Comparación de los deseos de fidelización de los encuestados con sus preferencias de estrategias de retención}

La cuarta relación estudiada se da entre la elección de los "deseos de fidelización» y las preferencias de "estrategias de retención» del grupo de jóvenes al que se le aplicó la encuesta de perfiles generacionales. 


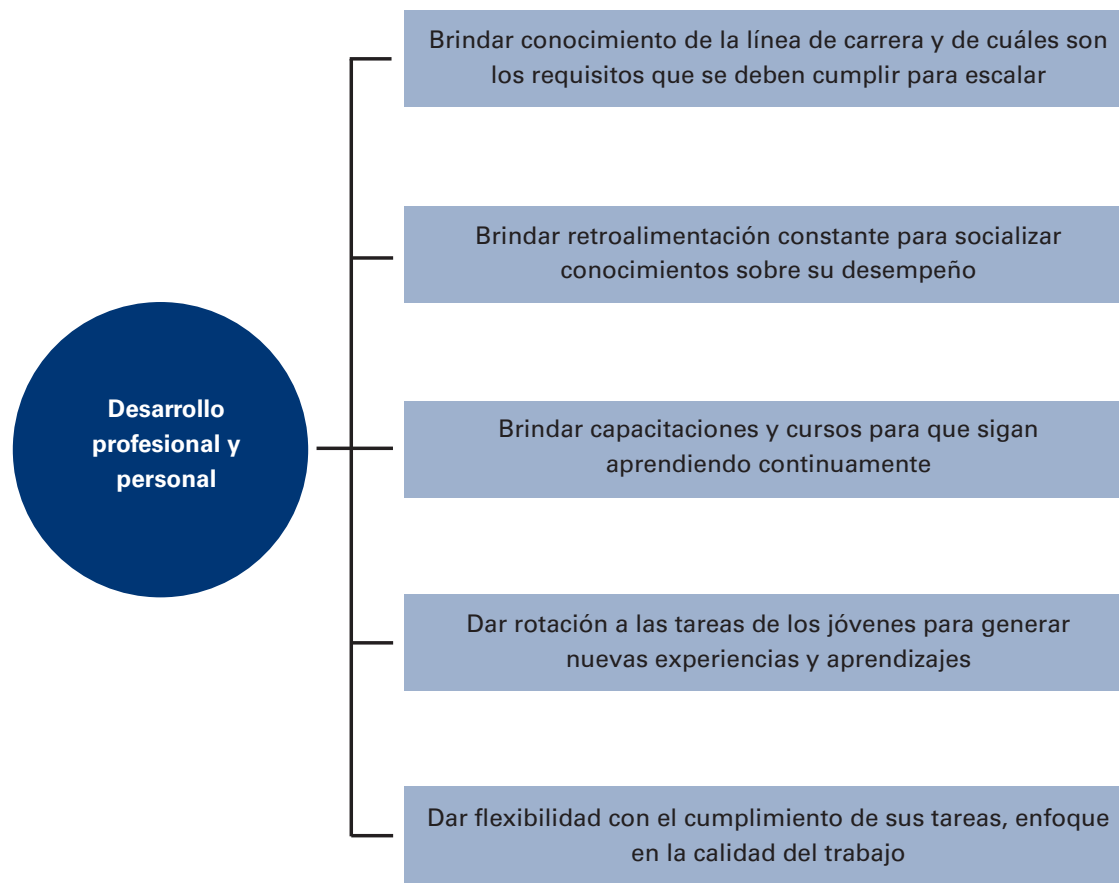

Fuente: Dávila y Mitta (2015, p. 90).

«Desarrollo profesional y personal» fue la opción más votada en la cartilla de "deseos de motivación», mientras que el orden de votación en la cartilla de "preferencias de estrategias de retención» fue el siguiente: línea de carrera, retroalimentación, capacitaciones y cursos, rotación de tareas y flexibilidad. Las estrategias de retención nombradas anteriormente guardan estrecha relación con el aprendizaje del colaborador (desarrollo profesional y personal) puesto que la línea de carrera le permite crecer dentro de la organización e irse desarrollando profesionalmente en diferentes puestos. Las capacitaciones y cursos también juegan un papel importante porque influyen directamente en los conocimientos adquiridos, pues mientras más capacitaciones reciba el colaborador, estará mejor preparado para asumir nuevos retos. Finalmente, la rotación de tareas permite que el colaborador aprenda y realice funciones diferentes, lo cual amplía sus conocimientos y le da la ventaja de desarrollar trabajos en diferentes áreas.

Es decir, si un colaborador está buscando desarrollo profesional y personal dentro de la organización, el área de recursos humanos puede cubrir esta necesidad ofreciéndole línea de carrera, retroalimentación del desarrollo de sus tareas, capacitaciones y cursos de formación continua y rotación de tareas. Todas estas estrategias generarán un mayor conocimiento en los colaboradores y se sentirán desarrollados personal y profesionalmente. 


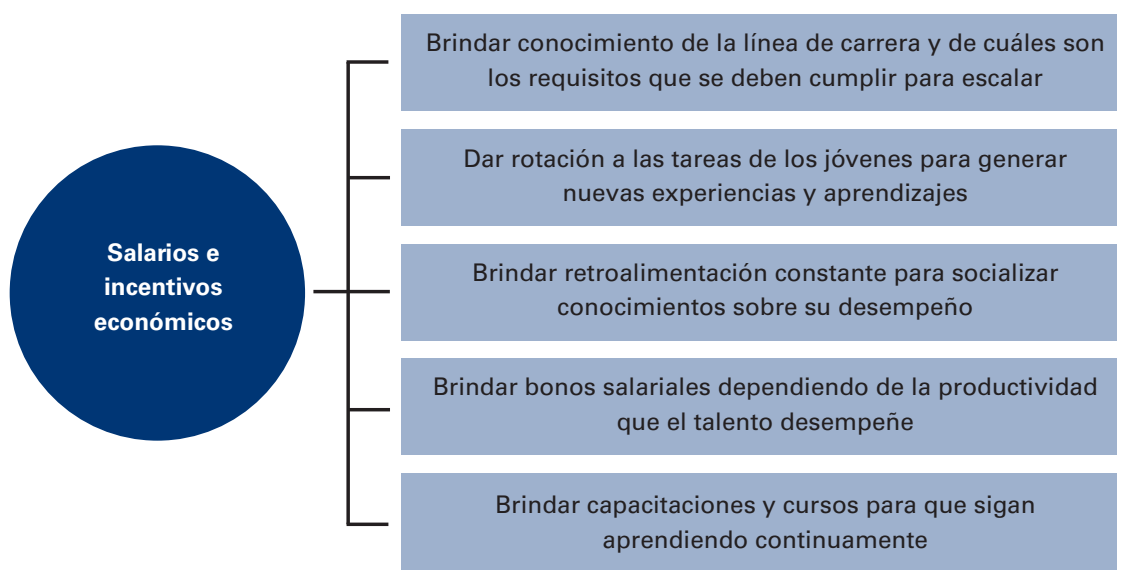

Fuente: Dávila y Mitta (2015, p. 91).

El salario e incentivo económico ha sido desplazado por otros factores y esto también se visualiza en los resultados de la encuesta. Salario e incentivos fueron la segunda opción más votada como deseo de motivación, mientras que las otras estrategias obtenidas fueron las siguientes: línea de carrera, rotación de tareas, retroalimentación, bonos salariales y capacitaciones y cursos. El salario en sí mismo como estrategia de retención ocupó el cuarto lugar, lo que ratifica lo dicho anteriormente. Asimismo, los resultados demuestran que existen "políticas no monetarias» que reemplazan el factor de motivación salarial, por ejemplo: la línea de carrera le permite al colaborador ascender en el organigrama de la organización, lo cual le generará mayores ingresos; las capacitaciones y cursos nutren al colaborador de mayor conocimiento, lo cual es recompensado con un ingreso mayor; e, indirectamente, la retroalimentación también nutre al colaborador de mayores conocimientos y de mejor manejo y resultado de sus tareas, lo cual también será premiado en la organización. Finalmente, la rotación de tareas otorga al colaborador mayor cantidad de conocimiento, lo cual es valorado en las organizaciones al buscar un trabajo.

Figura 8. Tercera opción: resultado de encuestas sobre «deseos»-«preferencias»

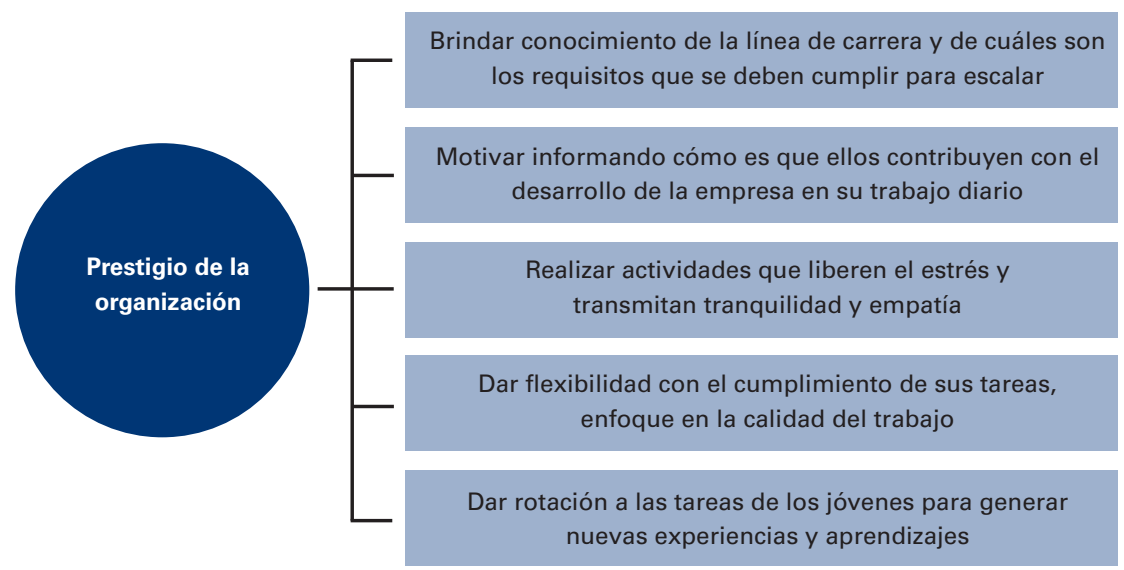


Cuando "prestigio de la organización» ocupó el primer lugar en la votación de los "deseos» de motivación, los resultados de las preferencias de estrategias de retención fueron: línea de carrera, motivarlos informándoles cómo contribuyen con el desarrollo de la organización, actividades que liberen el estrés, flexibilidad laboral y rotación de tareas. Es decir que el prestigio de la organización para un joven millennial universitario limeño encuestado está relacionado con la implementación de las estrategias ya mencionadas.

\subsection{Comparación entre los resultados de las preferencias de las políticas de retención de los encuestados y las políticas de retención de los millennials}

La quinta relación estudiada es entre la elección de "preferencia de las estrategias de retención» del grupo de jóvenes al que se le aplicó la encuesta y la información obtenida del marco teórico acerca de las estrategias de retención aplicadas a millennials.

En la cartilla 2 de "estrategias generales de retención» (ver anexo 4) se listó un grupo de catorce opciones consideradas como «preferencia de las estrategias de retención». A continuación presentamos el resultado de las más votadas y su relación con respecto a la teoría presentada en el marco teórico.

Figura 9. Resultado opciones de estrategias de retención (encuesta)

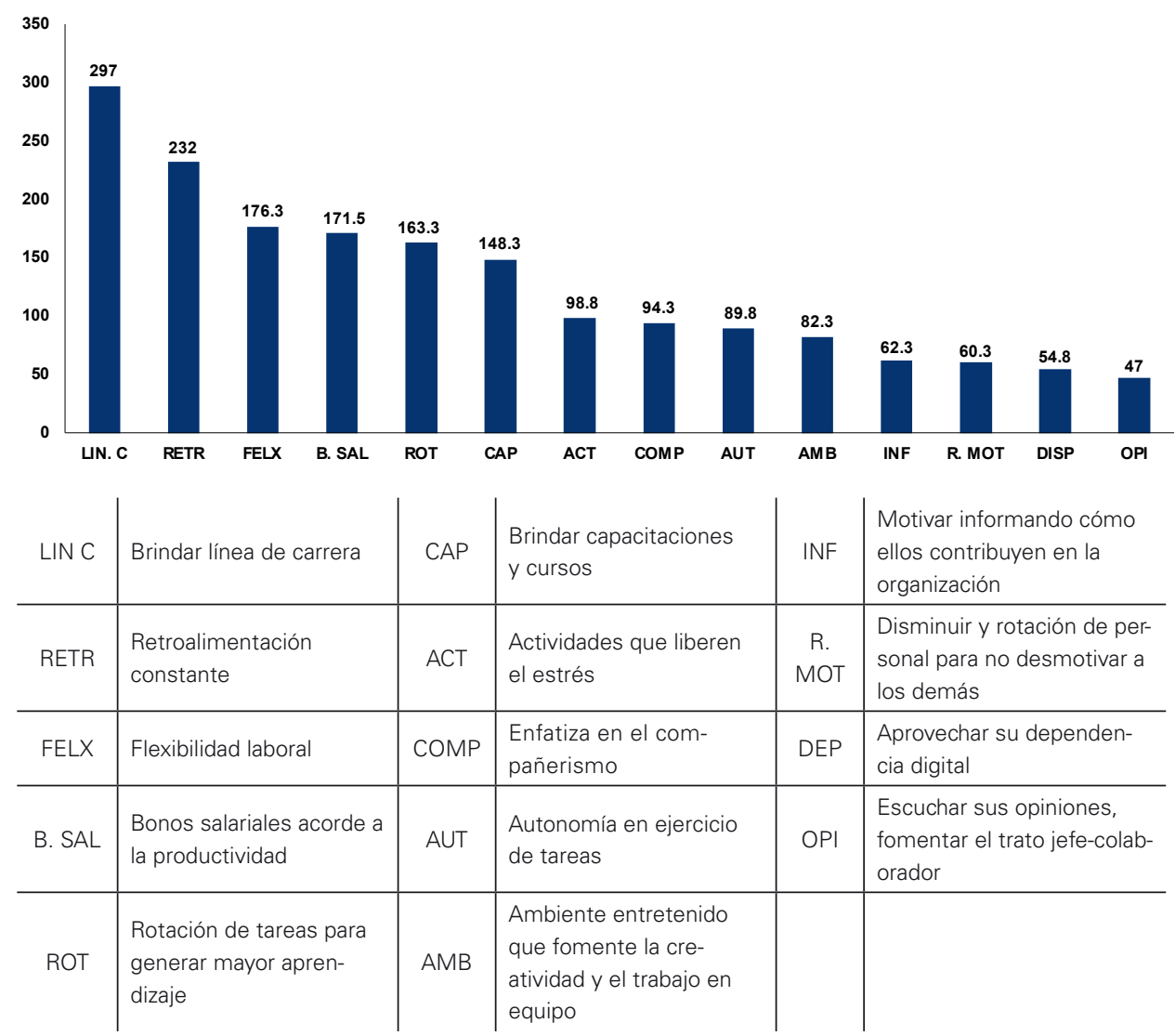


Podemos observar que la información obtenida en la encuesta aplicada al grupo de estudiantes acerca de las preferencias de estrategias de retención guarda relación con las estrategias de retención que vienen siendo aplicadas a los millennials en la actualidad; sin embargo, encontramos que el factor "línea de carrera» no debería estar dentro de las estrategias de retención aplicadas a los millennials encuestados. Este es un tema controversial ya que algunos investigadores peruanos afirman que los millennials buscan estabilidad laboral y línea de carrera, mientras que otros opinan que estos no piensan quedarse laborando en el mismo lugar de trabajo por más de dos años (Cafferata, 2013, p. 3); no obstante, según las estrategias de retención de los millennials norteamericanos, las organizaciones deberían permitir un crecimiento de línea de carrera más rápido por resultados y no por la cantidad de tiempo que toma ascender, aun considerando el buen desempeño y resultado de su trabajo (PwC, 2011, «b», p. 25).

Tabla 4. Estrategias de retención aplicadas a millennials según el perfil del millennial norteamericano

\title{
Lo que nos dice la teoría sobre estrategias de retención aplicadas a millennials
}

\author{
Ayudarlos a crecer a través de la rotación de tareas \\ Feedback \\ Flexibilidad \\ Mostrar valoración de las opiniones de los millennials \\ Apreciar las ventajas tecnológicas del nativo digital en vez de prohibirlas \\ Balance entre intereses personales y vida laboral \\ Motivación constante \\ Priorizar el trabajo en equipo \\ Brindar un ambiente de trabajo entretenido \\ Permitir un crecimiento de línea de carrera más rápido
}

Fuente: Dávila y Mitta (2015, p. 94).

Finalmente, podemos agregar que existe cierta similitud entre las estrategias de retención preferidas por los jóvenes millennials encuestados y la teoría presentada en nuestro marco teórico sobre las estrategias de retención aplicadas a los millennials norteamericanos. A pesar de ello, los resultados demuestran que es necesario que se desarrollen e implementen nuevas políticas de retención dirigidas netamente a los millennials encuestados pues estos presentan características y expectativas diferentes a las del millennial norteamericano promedio.

5.6. Comparación entre las preferencias de las estrategias de retención de los encuestados y las estrategias de retención implementadas por las organizaciones estudiadas

La última relación estudiada es entre las estrategias de retención que las áreas de recursos humanos del grupo de organizaciones entrevistadas aplican y la elección de «preferencia de las estrategias de retención» del grupo de jóvenes millennials universitarios encuestado. 
Recordemos que dentro del diseño de la encuesta había una parte designada a la elección de las estrategias según las preferencias del grupo encuestado; asimismo, la entrevista constaba de preguntas relevantes que indican cuáles son las estrategias de retención que las áreas de recursos humanos de las organizaciones seleccionadas vienen aplicando. A continuación, presentamos ambos resultados:

Tabla 5. Comparativo de resultados de la encuesta estrategias de retención

\begin{tabular}{|c|c|}
\hline $\begin{array}{c}\text { Resultados de la encuesta } \\
\text { en estrategias de retención preferidas } \\
\text { por los jóvenes encuestados }\end{array}$ & $\begin{array}{c}\text { Resultados de la entrevista } \\
\text { en estrategias de retención aplicadas } \\
\text { por las organizaciones }\end{array}$ \\
\hline Brindarle línea de carrera & Línea de carrera \\
\hline Retroalimentación constante & Capacitaciones y cursos \\
\hline Flexibilidad laboral & Actividades que liberen el estrés \\
\hline Bono salarial acorde a la productividad & Seguro médico \\
\hline Rotación de tareas para generar mayor aprendizaje & Préstamos de dinero \\
\hline Brindarle capacitaciones y cursos & Aumento salarial y bonos \\
\hline Realizar actividades que liberen el estrés & \\
\hline $\begin{array}{l}\text { Trabajar siempre en equipo, enfatizar el compañerismo, la } \\
\text { colaboración y la relación entre ellos }\end{array}$ & \\
\hline $\begin{array}{l}\text { Dar autonomía en relación a la manera de realizar las } \\
\text { tareas encargadas }\end{array}$ & \\
\hline $\begin{array}{l}\text { Brindar ambiente entretenido que fomente la creatividad } \\
\text { y trabajo en equipo }\end{array}$ & \\
\hline $\begin{array}{l}\text { Motivarlos informándoles cómo es que ellos contribuyen } \\
\text { con el desarrollo de la empresa en su trabajo diario }\end{array}$ & \\
\hline $\begin{array}{l}\text { Disminuir rotación de personal para no desmotivar a los } \\
\text { demás }\end{array}$ & \\
\hline $\begin{array}{l}\text { Aprovechar su dependencia digital, valorar su disponibi- } \\
\text { lidad para estar conectados a los medios sociales para } \\
\text { fines laborales }\end{array}$ & \\
\hline $\begin{array}{l}\text { Escuchar sus opiniones, fomentar el trato jefe-colabora- } \\
\text { dor }\end{array}$ & \\
\hline
\end{tabular}

Fuente: Dávila y Mitta (2015, p. 95).

Los resultados demuestran que la similitud entre los resultados sobre las preferencias en estrategias realizadas de parte de los encuestados en la encuesta y las estrategias que estas áreas de recursos humanos vienen aplicando radica en los siguientes puntos: línea de carrera, bonos salariales, actividades que liberen el estrés y capacitaciones y cursos.

Las organizaciones están cubriendo algunas de las estrategias preferidas por el grupo de jóvenes encuestados mediante la ejecución de políticas y prácticas de retención; sin embargo, aún falta cubrir algunos deseos de estos jóvenes como la retroalimentación, la flexibilidad laboral, el énfasis en el compañerismo, la rotación de tareas, la autonomía y el ambiente entretenido. Si bien estos deseos faltantes no se encuentran como estrategias establecidas, algunas de las organizaciones señalan que estas se están dando, pero dentro de la relación jefe-colaborador. 


\subsection{Discusión de los resultados}

A continuación, se discutirán los resultados y hallazgos del estudio en función de los objetivos planteados en la investigación.

\subsubsection{Hallazgos de la encuesta}

- Existen rasgos y características similares entre los jóvenes encuestados y el perfil del millennial norteamericano. Las características más resaltantes son: optimismo, colaboracionismo, el trabajo en equipo, la necesidad de feedback, el equilibrio entre la vida personal y laboral, y la alta conectividad a las redes sociales. Estas característica fueron votadas como propias por más del 70\% de los jóvenes encuestados.

- El grupo de jóvenes millennials universitarios encuestado cumple en 65.85\% con el perfil de millennial norteamericano. Las principales diferencias entre ambos fueron que los encuestados son realistas, innovan las reglas y su actitud frente al dinero es de despilfarro.

- El perfil del millennial encuestado se vio afectado por acontecimientos nacionales como el terrorismo, los conflictos sociales y la corrupción.

- Las estrategias de motivación y retención que este grupo de jóvenes encuestado prefiere son el desarrollo personal y profesional (aprendizaje), el salario y los incentivos económicos, y el prestigio de la organización donde laboran.

- Las estrategias de retención que estos jóvenes prefieren son la línea de carrera, la rotación de tareas, la flexibilidad laboral, la retroalimentación y las capacitaciones.

- Con respecto a los factores de motivación, los jóvenes encuestados prefieren el cubrimiento de factores extrínsecos e intrínsecos, y la aplicación de estrategias de retención que estén relacionadas con necesidades fisiológicas, de autorrealización, de reconocimiento y de afiliación.

- $\quad$ No se pueden aplicar las políticas de retención desarrolladas para millennials americanos en los millennials encuestados porque estos no son totalmente similares $y$, por ende, la respuesta de los mismos con respecto a esas políticas tendrá otros resultados.

\subsubsection{Hallazgos de las entrevistas}

- Mediante el análisis de las entrevistas se observan dos escenarios en los cuales este grupo de organizaciones se encuentra. A continuación, se detallarán los escenarios encontrados:

- Escenario 1: en este escenario se encontró que los encargados de las áreas de RR. HH. de las organizaciones seleccionadas no han implementado nuevas estrategias de retención dirigidas al personal millennial. Las áreas de recursos humanos del grupo de organizaciones 
seleccionadas tienen conocimiento sobre quiénes son los millennials, cuáles son sus características y qué importancia tienen en el mercado laboral. Si bien todas las organizaciones entrevistadas cuentan con personal considerado como millennial, no existen políticas de retención que estén segmentadas para este grupo. Es decir, a pesar de que las áreas de recursos humanos de estas organizaciones tienen idea de los beneficios que esta nueva generación demanda en el mercado laboral, ninguna de ellas ha modificado o implementado nuevas políticas a partir de la inserción laboral de esta nueva fuerza de trabajo.

- Escenario 2: en este segundo escenario se encontró que existen políticas de retención dirigidas a los millennials que se dan de manera informal mediante jefes directos. La mayoría de los gerentes entrevistados resaltaron que, a pesar de no tener formalmente políticas y prácticas que hayan sido creadas pensando en esta nueva generación, han observado que las relaciones jefe-colaborador millennial resuelve esta demanda de los jóvenes puesto que se les brindan los permisos, horarios flexibles, autonomía en las tareas, delegación de tareas desafiantes, entre otras cosas que ellos desean. Las estrategias no fueron diseñadas pensando estrictamente en la Generación Millennial; sin embargo, algunas sí cubren ciertos requerimientos de esta generación, mas no todos los que ellos desean.

- Los encargados de las áreas de recursos humanos del grupo de organizaciones entrevistadas respondieron en promedio que las estrategias de retención y fidelización que vienen aplicando a sus colaboradores millennials y no millennials son las siguientes: capacitaciones, cursos y becas de estudio; línea de carrera; seguro de salud para el colaborador $y$, en algunos casos, para sus padres; préstamos de dinero; buen clima laboral; paseos, salidas y actividades de recreación; aumento salarial y asignación de bonos.

- Las estrategias no fueron diseñadas pensando estrictamente en la Generación Millennial; no obstante, algunas sí cubren ciertos requerimientos de esta generación, mas no todos los que los millennials desean. Como se explicó en párrafos anteriores, se trata de una generación diferente a las previas y, como tal, tiene requerimientos distintos.

\section{Conclusiones de la investigación}

El término «rango generacional» hace referencia al concepto de "generación», el cual es definido como "un grupo de personas segmentadas por la edad que comparten una serie de experiencias formativas que las distinguen de sus predecesores» (Chirinos, 2009, p. 137). Según Howe y Strauss (citado en Rodríguez \& Peláez, 2010, pp. 161-164), estos deben cumplir tres atributos: el primero es la autopercepción de pertenencia a una determinada generación, empezando en la adolescencia y siguiendo hasta la fase de adultez. El segundo son las conductas, comportamientos y creencias comunes que caracterizan a una generación en diferentes aspectos de su vida personal, social y laboral. Por último, el tercer 
atributo se relaciona con la historia, hechos o situaciones importantes de cambio vividas tanto en las fases formativas como en la adolescencia o en la juventud.

En la actualidad algunos autores como Karsh y Templin, Chirinos, Howe y Strauss, entre otros, afirman que existen cinco generaciones que conviven entre sí; estas son: la generación de Los Tradicionales o Veteranos (1925-1945), los Baby Boomers (19461964), la Generación X (1965-1980), la Generación Y (1981-2000) y la Generación Z o los postmillennials, que son los nacidos a partir del año 2001. Se debe recalcar que las fechas mencionadas anteriormente son las que se han tomado en cuenta para efecto de esta investigación, partiendo de la propuesta de autores como Karsh, Templin y Kotler.

Los millennials son importantes no solo por sus diferencias con respecto a las generaciones anteriores, sino también porque es la segunda generación más numerosa después de los baby boomers, los cuales ya están transcurriendo las últimas etapas de la vida laboral. «En los Estados Unidos forman el 25\% de la fuerza laboral actual y en India más del 50\% [... ] se proyecta que para el año 2020, los Millennials serán el 50\% de la fuerza laboral global (PwC, 2011, "C», p. 3) y en nuestro país se estima que para el año 2025 estos equivaldrán al $60 \%$ de la fuerza laboral peruana» (CEPLAN, 2015, citado en Gestión, 2015). Como se mencionó, la personalidad de los jóvenes que se encuentran en los distintos rangos generacionales se moldea mediante los eventos históricos que experimentan. Es por ello que resulta relevante conocer las características de cada generación para tener una mejor gestión del talento, enfatizando en los temas que les interesan, brindando beneficios adecuados y aplicando políticas que permitan que los colaboradores sientan más cómodos con la organización en la que trabajan.

En el caso de los jóvenes encuestados, su deseo más fuerte, aquel que los impulsa a seguir creciendo, es el deseo de desarrollo profesional y personal, seguido del salario y el deseo de trabajar en una organización con prestigio. Añadido a esto, los jóvenes señalan que la mejor manera de retenerlos es mediante el otorgamiento de una línea de carrera, retroalimentación constante, flexibilidad laboral y bonos salariales, así como a través de la rotación de tareas. Tomando en cuenta la teoría de las expectativas de Victor Vroom, del año 1964, se puede afirmar que si los millennials perciben que es muy probable que se cumplan sus deseos motivacionales, como el de aprendizaje (desarrollo profesional y personal), entonces trabajarán muy motivados y eso generará grandes beneficios en la organización.

Siguiendo con los jóvenes encuestados, se encontró una relación entre el desarrollo personal como factor de motivación y las preferencias de las estrategias de retención —como brindarle línea de carrera, retroalimentación, capacitación, rotación de tareas y flexibilidad-. Esta relación nos permite inferir que, en el caso de estos jóvenes, brindarles las estrategias de retención mencionadas permite generar un sentimiento de desarrollo personal y profesional en ellos.

A través de entrevistas a encargados de áreas de recursos humanos parte de un grupo de organizaciones, se logró identificar cuáles son las estrategias que dicho grupo está implementando en la actualidad. Estas organizaciones están cubriendo la demanda básica de los jóvenes millennials encuestados brindando líneas de carrera; sin embargo, no tienen como estrategias definidas la retroalimentación constante, la flexibilidad laboral ni la rotación de tareas. Cabe resaltar que el no tener definidas estas estrategias no significa 
que no las estén implementando, pues se pueden estar dando bajo un trato colaboradorjefe como puede que no. Lo ideal es que estas estrategias, al ser tan valiosas para los millennials, deberían de ser estandarizadas y definidas correctamente por las áreas de recursos humanos. A los responsables se les preguntó si habían implementado políticas específicas para esta generación y respondieron que aún no, pero resaltaron que sí creían que se deberían implementar para poder retener a este segmento importante de talento.

En esta investigación, al presentar nuevas posibles tácticas o estrategias de retención dirigidas a los millennials, no se está discriminando o insinuando que se debe dejar de innovar y/o aplicar estrategias para el resto de generaciones en las organizaciones. Todo lo contrario, según la teoría de la gestión de la diversidad, se deben aprovechar las diferentes características que comparten los colectivos de trabajadores con el fin de poder generar un impacto positivo, mientras que la discriminación se basa en generar un efecto negativo en un individuo en base a sus características. Reforzando el concepto de innovación en gestión de la diversidad, Francisco Abad señala que «en una época en la que nadie será capaz de motivar fácilmente a nadie, salvo creando entornos que ayuden a que el otro crezca como persona, el planteamiento [de estrategias] no solo es válido para los Millenials, sino que es aplicable a todas las generaciones» (2015, p. 99).

\section{Recomendaciones}

Dado que esta investigación es solo exploratoria y de pequeña escala, se recomienda que el tema sea revisado a mayor profundidad, con un número más grande de encuestados que puedan representar a los jóvenes millennials del Perú y no únicamente a un segmento, como sucede en este estudio. Además, también se recomienda que se amplíe el número de entrevistas por el lado de las organizaciones con el fin de tener como mínimo una organización representativa de cada rubro y una cantidad representativa de todas las organizaciones peruanas.

También se recomienda implementar políticas de retención dirigidas a los millennials a través de los jefes directos. Cuando la organización compruebe el sentimiento de bienestar de estos colaboradores y su respuesta positiva a estas políticas, entonces tendrá una prueba para implementar estas nuevas políticas formalmente a nivel organizacional. Al haberse encontrado diferencias en el patrón de conducta entre el perfil del millennial norteamericano y el perfil del millennial encuestado, las organizaciones deberían considerar las estrategias de retención planteadas en esta investigación con el fin de poder retener el talento de aquellos millennials que tengan un perfil similar al aquí esbozado. Por el contrario, si se emplean estrategias enfocadas en el perfil del millennial norteamericano, puede que no sean del todo atractivas para los jóvenes que laboran en sus organizaciones.

Asimismo, las áreas de recursos humanos deben segmentar las políticas y prácticas de retención que aplican, por lo que necesitan conocer a fondo a los colaboradores de distintas generaciones, algo que pueden realizar a través de cualquier tipo de herramienta que provea información sobre el colaborador. A su vez, las organizaciones deben volverse atrayentes para la generación millennial para así poder seleccionar los mejores talentos. El Observatorio Generación \& Talento refuerza esta recomendación al señalar que «es esencial incorporar una estrategia integral con el fin de comprometer, motivar, retener y 
potenciar a personas de perfiles diversos que aporten innovación, nuevas opciones y puntos de vista diferentes, soluciones creativas, y conocimiento de las diversidades culturales y económicas de los mercados» (2018, p. 11).

Consideramos relevante que las organizaciones entrevistadas segmenten a sus trabajadores, puesto que si bien comparten una rotación baja de colaboradores, ello se puede deber a que los millennials aún no abarcan gran parte del mercado laboral; sin embargo, con el paso del tiempo, las generaciones anteriores se irán jubilando y será un reto mayor retener estos jóvenes, caracterizados por ser exigentes en sus expectativas y no permanecer mucho tiempo en un centro de trabajo. Capell refuerza esta recomendación señalando que «Un buen modo de conocer la opinión de los colaboradores es el uso de encuestas, [las cuales] permitirán reflejar las diferencias generacionales de modo que las políticas de gestión de personas puedan adaptarse y ser un reflejo de las mismas» (2018, p. 39). La respuesta que ofrecemos en base a la gestión de la diversidad y la existencia de diversos grupos generacionales en un ámbito laboral es la de crear paquetes de beneficios a elección en base a las estrategias de retención para cada generación; es decir, como organización, brindar paquetes millennial, baby boomery xers. Cabe recalcar que para que esta práctica no sea discriminatoria debe de dársele al colaborador la posibilidad de elegir qué paquete es el que más le atrae y todos los paquetes deben ser similares en costos. 


\section{Anexo 1}

\section{Información general de la encuesta}

Figura 10. Género de los participantes

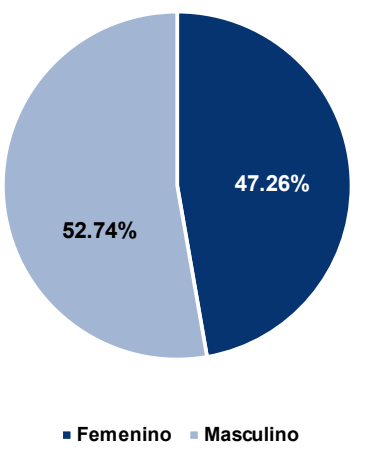

Figura 11. Rango de edad de los participantes

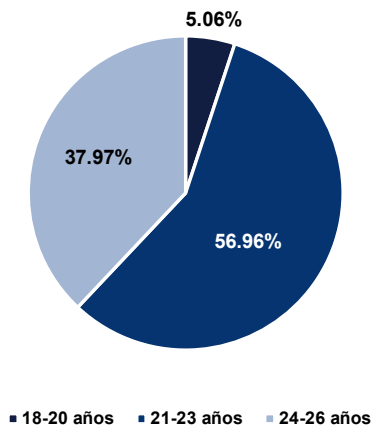

Figura 12. Carrera universitaria de los participantes

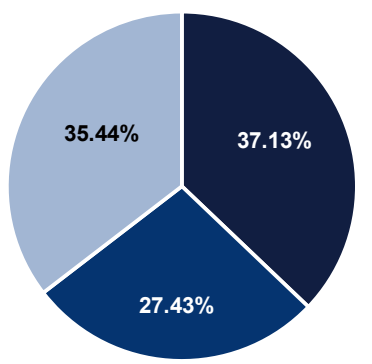

- Gestión y Alta Dirección Economía " Ingeniería Industrial
Figura 13. Ciclo cursado de los participantes

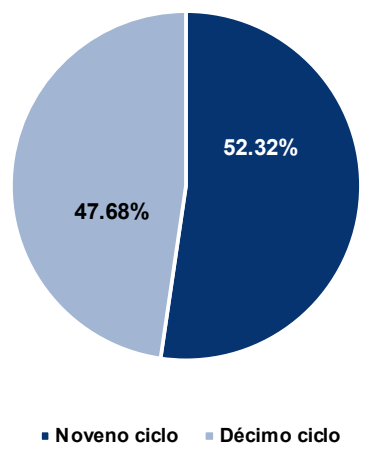

Figura 14. Experiencia laboral de los participantes (número de trabajos)

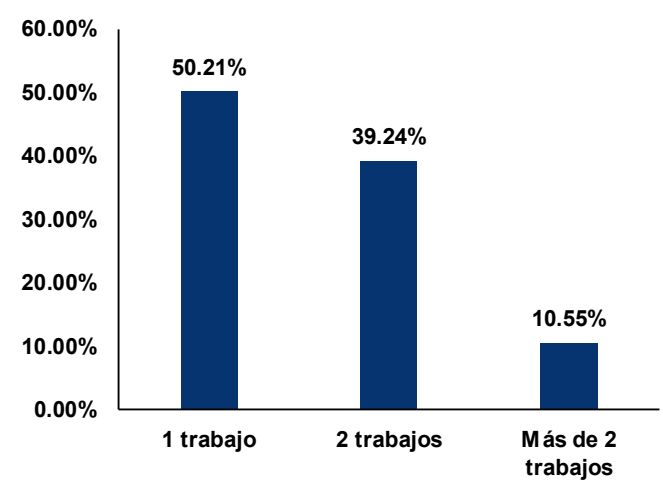

Figura 15. Experiencia laboral de los participantes (meses trabajados)

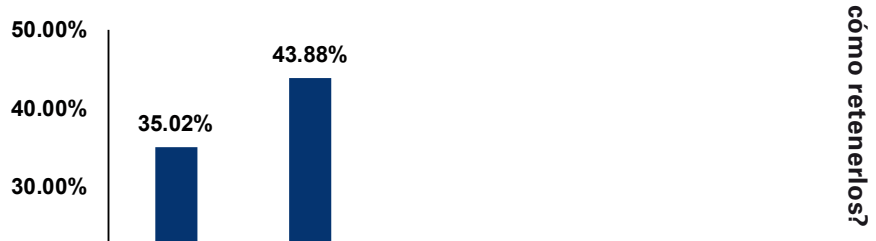




\section{Anexo 2}

\section{Cuadro comparativo de resultados comportamentales}

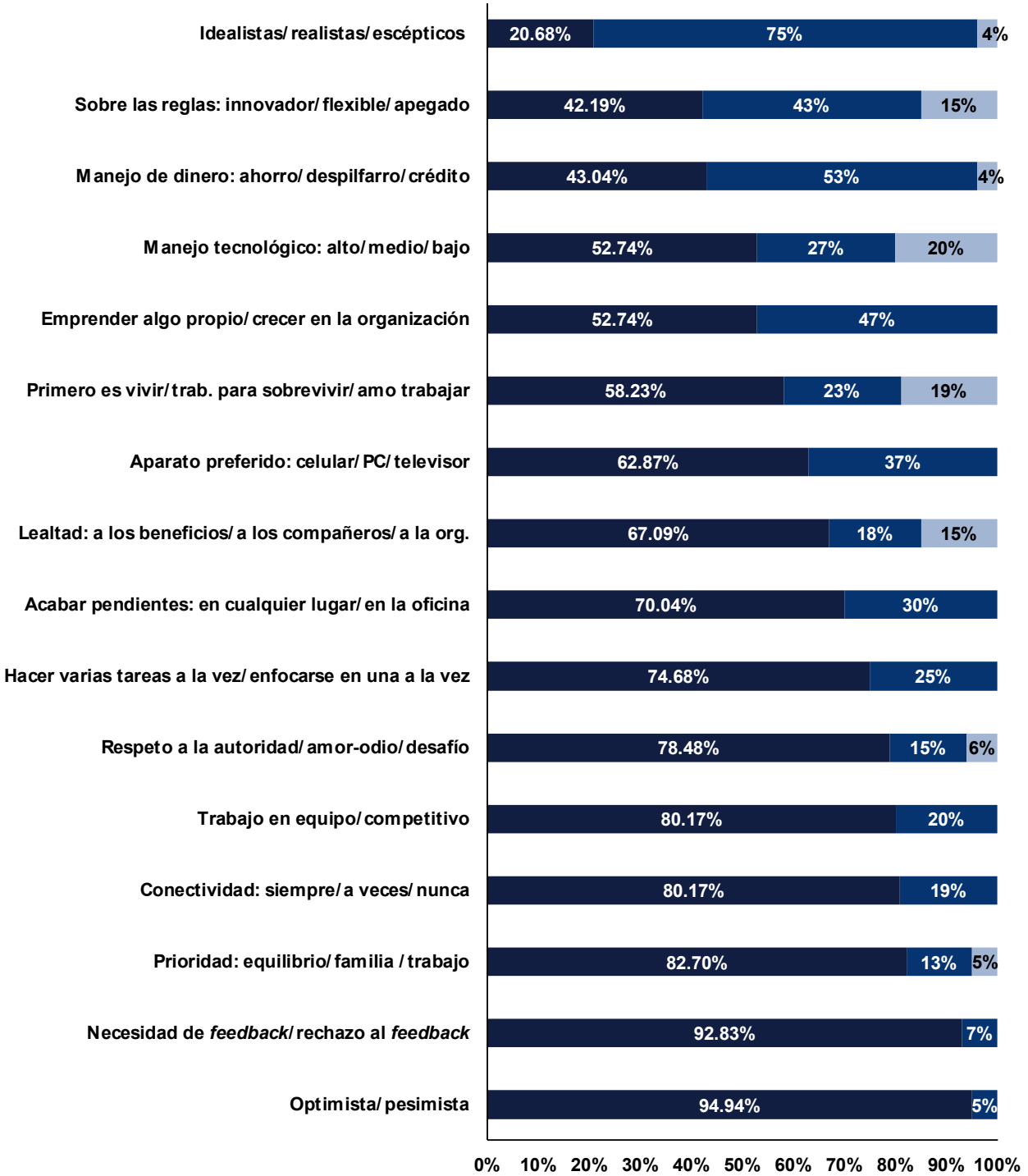


Anexo 3

Cartilla 1 (deseos)

\section{Cartilla 1. Deseos de fidelización}

\begin{tabular}{|c|c|}
\hline Opción & Motivo de fidelización \\
\hline A & Salario e incentivos económicos (bonos y salario por encima del promedio) \\
\hline B & Desarrollo personal y profesional (aprendizaje) \\
\hline $\mathbf{C}$ & Prestigio de la empresa \\
\hline D & Los objetivos de la empresa son similares a los míos \\
\hline $\mathbf{E}$ & Reconocimiento del desempeño \\
\hline $\mathbf{F}$ & Flexibilidad laboral (equilibrio trabajo-familia) \\
\hline G & Posibilidad de crecimiento en la empresa \\
\hline $\mathbf{H}$ & Relación fluida y de confianza con los supervisores \\
\hline I & La organización me brinda una sensación de seguridad y protección (estabilidad laboral) \\
\hline $\mathbf{J}$ & El trabajo en equipo es muy frecuente en la organización \\
\hline $\mathbf{K}$ & Celebran mi cumpleaños, aniversarios, bodas, entre otras actividades \\
\hline $\mathbf{L}$ & Trabajar en la organización es un reto profesional \\
\hline
\end{tabular}




\section{Anexo 4}

\section{Cartilla 2 (estrategias)}

\section{Cartilla 2. Estrategias de retención de personal tentativas}

\begin{tabular}{|c|c|}
\hline Opción & Estrategia de retención \\
\hline A & Darle rotación a las tareas de los jóvenes para generar nuevas experiencias y aprendizajes \\
\hline B & Brindar retroalimentación constante para socializar conocimientos sobre su desempeño \\
\hline C & Tener flexibilidad con el cumplimiento de sus tareas, enfoque en la calidad del trabajo \\
\hline D & Disminuir la rotación del personal para no desmotivar a los trabajadores con talento \\
\hline $\mathbf{E}$ & Brindar bonos salariales dependiendo de la productividad que el talento desempeñe \\
\hline $\mathbf{F}$ & Dar autonomía en relación a la manera de realizar las tareas encargadas \\
\hline G & Brindar capacitaciones y cursos para que sigan aprendiendo continuamente \\
\hline $\mathbf{H}$ & $\begin{array}{l}\text { Brindar conocimiento de la línea de carrera y de cuáles son los requisitos que deben cumplirse para } \\
\text { escalar }\end{array}$ \\
\hline $\mathbf{I}$ & Escuchar sus opiniones, fomentar el trato jefe-colaborador. \\
\hline $\mathbf{J}$ & $\begin{array}{l}\text { Aprovechar su dependencia digital, valorar su permanente conexión a los medios sociales para } \\
\text { fines laborales }\end{array}$ \\
\hline $\mathbf{K}$ & Realizar actividades que liberen el estrés y transmitan tranquilidad y empatía \\
\hline $\mathbf{L}$ & $\begin{array}{l}\text { Motivar informando cómo es que ellos contribuyen con el desarrollo de la empresa en su trabajo } \\
\text { diario }\end{array}$ \\
\hline M & Trabajar siempre en equipo, enfatizar el compañerismo, colaboración y relación entre ellos \\
\hline $\mathbf{N}$ & $\begin{array}{l}\text { Brindar un ambiente entretenido, buscando incentivar la innovación, la creatividad, el buen ambi- } \\
\text { ente laboral y el trabajo en equipo }\end{array}$ \\
\hline
\end{tabular}




\section{bibliografía}

\section{Abad F.}

2015

Tendencias en la gestión de la diversidad generacional en el mundo laboral. Capital Humano, 28(302), 98. Recuperado de: http://ezproxybib.pucp.edu.pe:2048/ login?url=http://search.ebscohost.com/ login. aspx? direct $=$ true $\& d b=e d b \& A N=1128$ 28802\&lang=es\&site=eds-live \&scope=site

\section{Cafferata, R.}

2013 La Generación del Milenio. Punto Edu., pp. 2-4. Recuperado de: https://es.scribd. com/doc/170318466/PuntoEdu-Ano-9numero-282013\#

\section{Cantu, L.}

Factores que se aplican para la atracción y retención de personal en organizaciones grandes de manufactura del estado de Nueva León (proyecto final de campo para maestría en psicología laboral). Universidad Autónoma de Nuevo León, Nuevo León, México. Recuperado de: http://eprints.uanl. $m \times / 5584 /$

\section{Capell, J.}

2018 Captar y retener talento de diferentes generaciones: baby boomers, Generación X, millenials. Capital Humano, 31(335), 38. Recuperado de: http://ezproxybib. pucp.edu.pe:2048/login?url=http://search. ebscohost.com/login.aspx?direct=true\&d $b=e d b \& A N=132019882 \&$ lang $=e s \&$ site $=e$ ds-live\&scope $=$ site

\section{Capital Humano}

Diversidad e inclusión social, un espejo para las empresas. Capital Humano, 31(331), 43. Recuperado de: http://ezproxybib.pucp.edu.pe:2048/ login?url=http://search.ebscohost.com/ login.aspx? direct=true $\& \mathrm{db}=\mathrm{edb} \& \mathrm{AN}=1292$

76805\&lang=es\&site=eds-live \&scope=site

\section{Casanova, M.}

2006 Unidad de conocimiento - La gestión de la diversidad. España: Fundación $\mathrm{RH}$. Recuperado de: http://www.factorhuma. org/attachments_secure/article/8304/ diversitat_cast.pdf

\section{Castillo, C.}

2009 Nuevas tendencias en la retención y mejora del talento profesional directivo. Fundación EOI. Recuperado de: http:// www.eoi.es/savia/documento/eoi-12007/ nuevas-tendencias-en-la-retencion-ymejora-del-talento-profesional-y-directivo

\section{Castillo, M., \& Suso, A.}

La gestión de la diversidad: por una estrategia de gestión de la edad y de la discapacidad en las empresas. España. Red2Red Consultores. Recuperado de: http://www.fundaciononce.es/sites/default/ files/docs/Libro_Diversidad_Accesible_2. pdf

\section{Gestión}

Los Millennials - Características. 4 de marzo.

\section{Chirinos, N.}

Características generacionales y valores: su impacto en lo laboral. Observatorio Laboral Revista Venezolana, 2(4), 135-152. Recuperado de: http://www.redalyc.org/ pdf/2190/219016846007.pdf 


\section{bibliografía}

Cuesta, M., Ibáñez, M., Tagliabue, R., \& Zangaro, M.

2009

La nueva generación y el trabajo. Santa

Cruz do Sul. Recuperado de: https://online.

unisc.br/seer/index.php/barbaroi/article/

viewFile/479/908

Dávila, L., \& Mitta, D.

2015

Retención del talento humano:

políticas y prácticas aplicadas sobre

jóvenes "millennials» en un grupo de

organizaciones (tesis de licenciatura).

Pontificia Universidad Católica del Perú,

Lima, Perú. Recuperado de: http://tesis.

pucp.edu.pe/repositorio/bitstream/

handle/20.500.12404/6948/MITTA_

DANIEL_DAVILA_CARMEN_RETENCION.

pdf? sequence $=1$ \&isAllowed $=\mathrm{y}$

Dessler, G., \& Varela, R.

2004

Administración de recursos humanos.

Enfoque latinoamericano. Segunda edición.

Madrid: Pearson.

Hernández, R., Fernández, C., \&

Baptista, P.

2010 Metodología de la investigación. México

D. F.: McGraw - Hill Interamericana.

Howe, N., \& Strauss, W.

1991 Generations: The History of America's

Future, 1584 to 2069. Nueva York: William

Morrow \& Company.

Karsh, B., \& Templin, C.

2013 Manager 3.0: A Millennial's Guide to

Rewriting the Rules of Management

[Version Kindle]. AMACOM.

\section{Observatorio Generación \&}

Talento

s.f. Diagnóstico de la diversidad generacional: análisis del talento intergeneracional en las empresas. Recuperado de: https:// www.meta4.es/files/informes/Diagnosticodiversidad-generacional-rrhh-meta4.pdf

\section{Pew Research Center}

2010

Millennials, A Portrait of Generation Next. Research Review. Recuperado de: https:// www.pewsocialtrends.org/2010/02/24/ millennials-confident-connected-open-tochange/

\section{PricewaterhouseCoopers [PwC]}

2011

Millennials at Work. Reshaping the Workplace. Recuperado de: https://www. pwc.de/de/prozessoptimierung/assets/ millennials-at-work-2011.pdf

\section{Prieto, P.}

2013

Gestión del talento humano como estrategia para retención del personal (tesis de especialización). Universidad de Medellín, Medellín, Colombia. Recuperado de: http://repository.udem. edu.co/bitstream/handle/11407/160/ Gesti\%C3\%B3n\%20del\%20talento\%20 humano $\% 20$ como $\% 20$ estrategia $\% 20$ para\%20retenci\%C3\%B3n\%20del\%20 personal.pdf? sequence $=1$

\section{Rodríguez, E., \& Peláez, M.}

La convivencia de diferentes generaciones en la empresa: compatibilización y liderazgo integral. XIV Congreso de Ingeniería de Organización. Donostia, San Sebastián. Recuperado de: http://adingor. es/congresos/web/uploads/cio/cio2010/ BUSINESS_ADMINISTRATION/160-170.pdf

\section{Santacruz, F.}

humana en la efectividad para retener el 


\section{bibliografía}

talento dentro de la organización (tesis de maestría). Universidad Nacional de Colombia, Manizales, Colombia. Recuperado de: http://docplayer. es/2328121-Francisco-javier-santacruzvillegas.html

\section{United Nations Joint Staff} Pension Fund

$X$, Generation $Y$ working together.

Recuperado de: http://aspringer. weebly.com/uploads/1/3/6/4/1364481/ designing_recruitment_selection__talent_ management_model_tailored_to_meet_ unjspfs_business_development_nee.pdf

\section{US American Chamber of}

\section{Commerce}

2012 The Millennials Generation Research

Review. Recuperado de: http://

www.uschamberfoundation.org/

sites/default/files/article/foundation/

MillennialGeneration.pdf

\section{Valdiviezo, C.}

2014 La Generación Y peruana: los mayores se comportan como $X$, solo los jóvenes $y$ adinerados, como Y. Semana Económica. Recuperado de: http://semanaeconomica. com/article/empresa/gerencia/139235generacion-y-peruana-losmayores-secomportan-como-x-solo-los-jovenes-yadinerados-como-y

Fecha de recepción: 30 de abril de 2018

Fecha de aceptación: 21 de febrero de 2019 